Cochrane Database of Systematic Reviews

\title{
Cannabis for the treatment of Crohn's disease (Review)
}

Kafil TS, Nguyen TM, MacDonald JK, Chande N

Kafil TS, Nguyen TM, MacDonald JK, Chande N.

Cannabis for the treatment of Crohn's disease.

Cochrane Database of Systematic Reviews 2018, Issue 11. Art. No.: CD012853.

DOI: 10.1002/14651858.CD012853.pub2.

www.cochranelibrary.com 
TABLE OF CONTENTS

ABSTRACT

PLAIN LANGUAGE SUMMARY

SUMMARY OF FINDINGS

BACKGROUND

OBJECTIVES

METHODS

RESULTS

Figure 1.

Figure 2.

DISCUSSION

AUTHORS' CONCLUSIONS

ACKNOWLEDGEMENTS

REFERENCES

CHARACTERISTICS OF STUDIES

DATA AND ANALYSES

Analysis 1.1. Comparison 1 Cannabis cigarettes (115 mg THC) versus placebo cigarettes, Outcome 1 Clinical remission at 8 weeks.

Analysis 1.2. Comparison 1 Cannabis cigarettes (115 mg THC) versus placebo cigarettes, Outcome 2 Clinical response at 8 weeks.

Analysis 1.3. Comparison 1 Cannabis cigarettes (115 mg THC) versus placebo cigarettes, Outcome 3 Adverse events.

Analysis 1.4. Comparison 1 Cannabis cigarettes (115 mg THC) versus placebo cigarettes, Outcome 4 Decrease in CRP of more than $0.5 \mathrm{mg} / \mathrm{dL}$ from week 0 to week 8 .

Analysis 2.1. Comparison 2 Cannabis oil (5\% cannabidiol sublingual oil) versus placebo oil, Outcome 1 Clinical remission at 8 weeks.

Analysis 2.2. Comparison 2 Cannabis oil ( $5 \%$ cannabidiol sublingual oil) versus placebo oil, Outcome 2 Serious adverse events.

Analysis 3.1. Comparison 3 Cannabis oil (15\% cannabidiol and 4\% THC) versus placebo oil, Outcome 1 Quality of life at 8 weeks.

Analysis 3.2. Comparison 3 Cannabis oil (15\% cannabidiol and 4\% THC) versus placebo oil, Outcome 2 CDAl at 8 weeks. ........ 27 APPENDICES

WHAT'S NEW

HISTORY

CONTRIBUTIONS OF AUTHORS

DECLARATIONS OF INTEREST

DIFFERENCES BETWEEN PROTOCOL AND REVIEW

INDEX TERMS 
[Intervention Review]

\section{Cannabis for the treatment of Crohn's disease}

Tahir S Kafil ${ }^{1}$, Tran M Nguyen², John K MacDonald ${ }^{1,2}$, Nilesh Chande 3

1Department of Medicine, University of Western Ontario, London, Canada. ${ }^{2}$ Cochrane IBD Group, Robarts Clinical Trials, London, Canada.

3London Health Sciences Centre - Victoria Hospital, London, Canada

Contact: John K MacDonald, Cochrane IBD Group, Robarts Clinical Trials, 100 Dundas Street, Suite 200, London, ON, Canada. jmacdon1@uwo.ca, john.macdonald@robartsinc.com.

Editorial group: Cochrane IBD Group.

Publication status and date: Edited (no change to conclusions), published in Issue 6, 2019.

Citation: Kafil TS, Nguyen TM, MacDonald JK, Chande N. Cannabis for the treatment of Crohn's disease. Cochrane Database of Systematic Reviews 2018, Issue 11. Art. No.: CD012853. DOI: 10.1002/14651858.CD012853.pub2.

Copyright (c 2019 The Cochrane Collaboration. Published by John Wiley \& Sons, Ltd.

\section{A B S T R A C T}

\section{Background}

Crohn's disease (CD) is a chronic immune-mediated condition of transmural inflammation in the gastrointestinal tract, associated with significant morbidity and decreased quality of life. The endocannabinoid system provides a potential therapeutic target for cannabis and cannabinoids and animal models have shown benefit in decreasing inflammation. However, there is also evidence to suggest transient adverse events such as weakness, dizziness and diarrhea, and an increased risk of surgery in people with CD who use cannabis.

\section{Objectives}

The objectives were to assess the efficacy and safety of cannabis and cannabinoids for induction and maintenance of remission in people with CD.

\section{Search methods}

We searched MEDLINE, Embase, AMED, PsychINFO, the Cochrane IBD Group Specialized Register, CENTRAL, ClinicalTrials.Gov, and the European Clinical Trials Register up to 17 October 2018. We searched conference abstracts, references and we also contacted researchers in this field for upcoming publications.

\section{Selection criteria}

Randomized controlled trials comparing any form of cannabis or its cannabinoid derivatives (natural or synthetic) to placebo or an active therapy for adults with Crohn's disease were included.

\section{Data collection and analysis}

Two authors independently screened search results, extracted data and assessed bias using the Cochrane risk of bias tool. The primary outcomes were clinical remission and relapse. Remission is commonly defined as a Crohn's disease activity index (CDAI) of $\leq 150$. Relapse is defined as a CDAI > 150. Secondary outcomes included clinical response, endoscopic remission, endoscopic improvement, histological improvement, quality of life, C-reactive protein (CRP) and fecal calprotectin measurements, adverse events (AEs), serious AEs, withdrawal due to $A E s$, and cannabis dependence and withdrawal effects. We calculated the risk ratio (RR) and corresponding 95\% confidence interval $(95 \% \mathrm{Cl})$ for dichotomous outcomes. For continuous outcomes, we calculated the mean difference (MD) and 95\% Cl. Data were combined for analysis when the interventions, patient groups and outcomes were sufficiently similar (determined by consensus). Data were analyzed on an intention-to-treat basis and the overall certainty of the evidence supporting the outcomes was evaluated using the GRADE criteria.

\section{Main results}

Three studies (93 participants) that assessed cannabis in people with active CD met the inclusion criteria. One ongoing study was also identified. Participants in two of the studies were adults with active Crohn's disease who had failed at least one medical treatment. The 
inclusion criteria for the third study were unclear. No studies that assessed cannabis therapy in quiescent CD were identified. The studies were not pooled due to differences in the interventional drug.

One small study ( $N=21)$ compared eight weeks of treatment with cannabis cigarettes containing 115 mg of D9-tetrahydrocannabinol (THC) to placebo cigarettes containing cannabis with the THC removed in participants with active CD. This study was rated as high risk of bias for blinding and other bias (cannabis participants were older than placebo). The effects of cannabis on clinical remission were unclear. Forty-five per cent (5/11) of the cannabis group achieved clinical remission compared with 10\% (1/10) of the placebo group (RR 4.55, 95\% $\mathrm{Cl} 0.63$ to 32.56; very low certainty evidence). A difference was observed in clinical response (decrease in CDAI score of $>100$ points) rates. Ninety-one per cent (10/11) of the cannabis group achieved a clinical response compared to 40\% (4/10) of the placebo group (RR $2.27,95 \%$ $\mathrm{Cl} 1.04$ to 4.97; very low certainty evidence). More AEs were observed in the cannabis cigarette group compared to placebo (RR 4.09, $95 \%$ $\mathrm{Cl} 1.15$ to 14.57 ; very low certainty evidence). These AEs were considered to be mild in nature and included sleepiness, nausea, difficulty with concentration, memory loss, confusion and dizziness. This study did not report on serious AEs or withdrawal due to AEs.

One small study ( $N=22$ ) compared cannabis oil ( $5 \%$ cannabidiol) to placebo oil in people with active $C D$. This study was rated as high risk of bias for other bias (cannabis participants were more likely than placebo participants to be smokers). There was no difference in clinical remission rates. Forty per cent (4/10) of cannabis oil participants achieved remission at 8 weeks compared to 33\% (3/9) of the placebo participants (RR $1.20,95 \% \mathrm{Cl} 0.36$ to 3.97 ; very low certainty evidence). There was no difference in the proportion of participants who had a serious adverse event. Ten per cent (1/10) of participants in the cannabis oil group had a serious adverse event compared to $11 \%(1 / 9)$ of placebo participants (RR $0.90,95 \% \mathrm{Cl} 0.07$ to 12.38 , very low certainty evidence). Both serious AEs were worsening Crohn's disease that required rescue intervention. This study did not report on clinical response, CRP, quality of life or withdrawal due to AEs.

One small study ( $\mathrm{N}=50)$ compared cannabis oil (15\% cannabidiol and 4\% THC) to placebo in participants with active CD. This study was rated as low risk of bias. Differences in CDAI and quality of life scores measured by the SF-36 instrument were observed. The mean quality of life score after 8 weeks of treatment was 96.3 in the cannabis oil group compared to 79.9 in the placebo group (MD $16.40,95 \% \mathrm{Cl} 5.72$ to 27.08 , low certainty evidence). After 8 weeks of treatment, the mean CDAl score was 118.6 in the cannabis oil group compared to 212.6 in the placebo group (MD $-94.00,95 \% \mathrm{Cl}-148.86$ to -39.14 , low certainty evidence). This study did not report on clinical remission, clinical response, CRP or AEs.

\section{Authors' conclusions}

The effects of cannabis and cannabis oil on Crohn's disease are uncertain. Thus no firm conclusions regarding the efficacy and safety of cannabis and cannabis oil in adults with active Crohn's disease can be drawn. The effects of cannabis or cannabis oil in quiescent Crohn's disease have not been investigated. Further studies with larger numbers of participants are required to assess the potential benefits and harms of cannabis in Crohn's disease. Future studies should assess the effects of cannabis in people with active and quiescent Crohn's disease. Different doses of cannabis and delivery modalities should be investigated.

\section{PLAIN LANGUAGE SUMMARY}

\section{Cannabis and cannabis oil for the treatment of Crohn's disease}

\section{What is Crohn's disease?}

Crohn's disease is a long-term condition that results in inflammation of the gastrointestinal tract, occurring anywhere from the mouth to the anus. Common symptoms include fever, diarrhoea, abdominal pain and weight loss. Crohn's disease is characterized by periods of relapse when people are actively experiencing symptoms and periods of remission when the symptoms stop.

\section{What are Cannabis and Cannabinoids?}

Cannabis is a widely used drug which acts on the endocannabinoid system. Cannabis contains multiple components called cannabinoids. The use of cannabis and cannabis oil containing specific cannabinoids produces mental and physical effects such as altered sensory perception and euphoria when consumed. Some cannabinoids, such as cannabidiol, do not have a psychoactive effect. Cannabis and cannabidiol have some anti-inflammatory properties that might help people with Crohn's disease.

\section{What did the researchers investigate?}

The researchers studied whether cannabis is better than placebo (e.g. a sugar pill) therapy for treating adults with active Crohn's disease or Crohn's disease that is in remission.

\section{What did the researchers find?}

The researchers extensively searched the literature up to 17 October 2018 and found three studies (93 participants) that met the inclusion criteria. One ongoing study was also identified. All of the studies were small in size and had some quality issues. One small study (21 participants) compared eight weeks of treatment with cannabis cigarettes containing $115 \mathrm{mg}$ of D9-tetrahydrocannabinol (THC) to placebo cigarettes containing cannabis with the THC removed in participants with active Crohn's disease who had failed at least one medical treatment. Although no difference in clinical remission rates was observed, more participants in the cannabis group had improvement 
in their Crohn's disease symptoms than participants in the placebo group. More side effects were observed in the cannabis cigarette group compared to placebo. These side effects were considered to be mild in nature and included sleepiness, nausea, difficulty with concentration, memory loss, confusion and dizziness. Participants in the cannabis cigarette group reported improvements in pain, appetite and satisfaction with treatment.

One small study (22 participants) compared cannabis oil (10 mg of cannabidiol twice daily) to placebo oil (i.e. olive oil) in participants with active Crohn's disease who had failed at least one medical treatment. No difference in clinical remission rates was observed. There was no difference in serious side effects. Serious side effects included worsening Crohn's disease in one participant in each group.

One small study (50 participants) compared cannabis oil (composed of $15 \%$ cannabidiol and $4 \%$ THC) to placebo oil in participants with active Crohn's disease. Positive differences in quality of life and the Crohn's disease activity index were observed.

\section{Conclusions}

The effects of cannabis and cannabis oil on Crohn's disease are uncertain. No firm conclusions regarding the benefits and harms (e.g. side effects) of cannabis and cannabis oil in adults with Crohn's disease can be drawn. The effects of cannabis and cannabis oil in people with Crohn's disease in remission have not been investigated. Further studies with larger numbers of participants are required to assess the potential benefits and harms of cannabis in Crohn's disease. Future studies should assess the effects of cannabis in people with active and inactive Crohn's disease. Different doses of cannabis and formulations (e.g. cannabis oil or pills) should be investigated. 


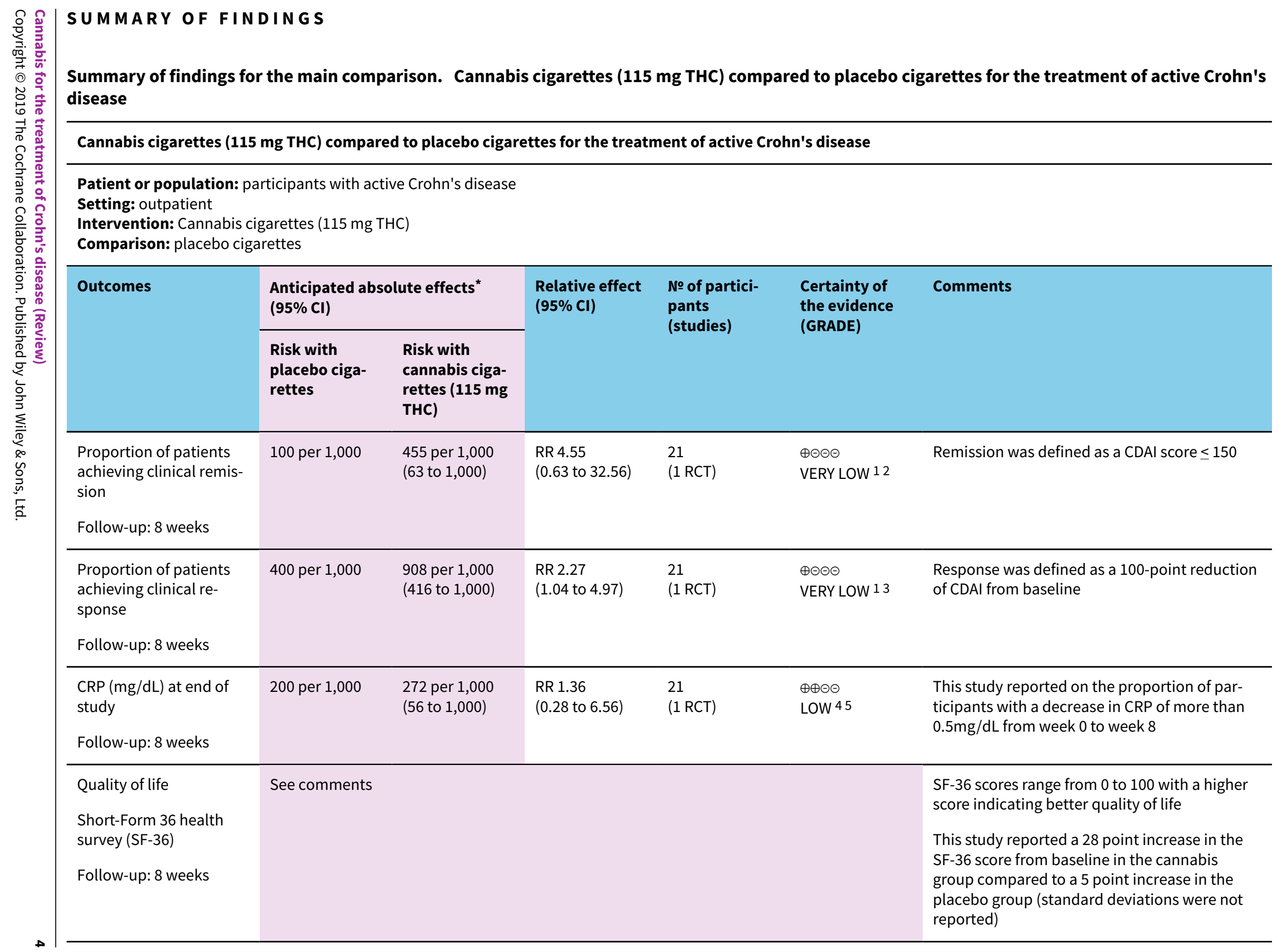




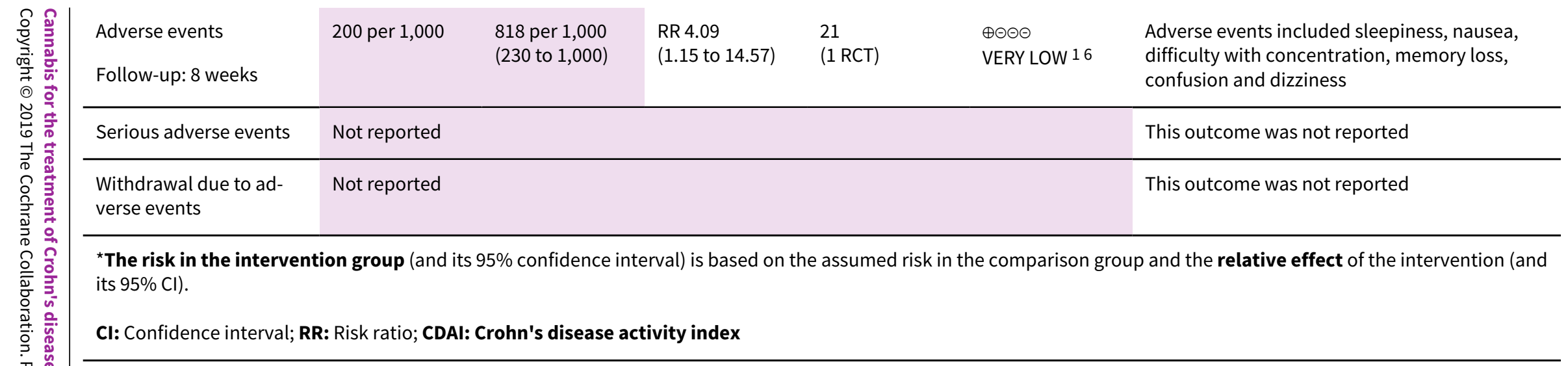

\section{GRADE Working Group grades of evidence}

High certainty: We are very confident that the true effect lies close to that of the estimate of the effect

Moderate certainty: We are moderately confident in the effect estimate: The true effect is likely to be close to the estimate of the effect, but there is a possibility that it is substantially different

Low certainty: Our confidence in the effect estimate is limited: The true effect may be substantially different from the estimate of the effect

Very low certainty: We have very little confidence in the effect estimate: The true effect is likely to be substantially different from the estimate of effect

1 Downgraded one level due to high risk of bias for blinding of participants and other bias (cannabis participants were about 10 years older than placebo participants)

2 Downgraded two levels due to very serious imprecision (6 events)

3 Downgraded two levels due to very serious imprecision (14 events)

4 We did not downgrade for risk of bias as this would have no impact on CRP which is an objective outcome

5 Downgraded two levels due to very serious imprecision (5 events)

6 Downgraded two levels due to very serious imprecision (11 events)

\section{Summary of findings 2. Cannabis oil ( $5 \%$ cannabidiol sublingual oil) compared to placebo oil for the treatment of active Crohn's disease}

\section{Cannabis oil (5\% cannabidiol sublingual oil) compared to placebo for the treatment of active Crohn's disease}

Patient or population: participants with active Crohn's disease

Setting: outpatient

Intervention: cannabis oil ( $5 \%$ cannabidiol sublingual oil)

Comparison: placebo oil (olive oil)

\begin{tabular}{|l|l|l|l|l|}
\hline Outcomes & $\begin{array}{l}\text { Anticipated absolute effects } \\
(95 \% \mathrm{Cl})\end{array}$ & $\begin{array}{l}\text { Relative effect } \\
(95 \% \mathrm{CI})\end{array}$ & $\begin{array}{l}\text { № of partici- } \\
\text { pants } \\
\text { (studies) }\end{array}$ & $\begin{array}{l}\text { Certainty of } \\
\text { the evidence } \\
\text { (GRADE) }\end{array}$ \\
\cline { 1 - 3 } & $\begin{array}{l}\text { Risk with } \\
\text { placebo }\end{array}$ & $\begin{array}{l}\text { Risk with } \\
\text { cannabis oil } \\
(5 \% \text { cannabid- }\end{array}$ & & \\
\hline
\end{tabular}




\begin{tabular}{|c|c|c|c|c|c|c|}
\hline & & $\begin{array}{l}\text { iol sublingual } \\
\text { oil) }\end{array}$ & & & & \\
\hline $\begin{array}{l}\text { Proportion of patients } \\
\text { achieving clinical remis- } \\
\text { sion } \\
\text { Follow-up: } 8 \text { weeks }\end{array}$ & 333 per 1,000 & $\begin{array}{l}400 \text { per } 1,000 \\
(120 \text { to } 1,000)\end{array}$ & $\begin{array}{l}\text { RR } 1.20 \\
\text { (0.36 to } 3.97)\end{array}$ & $\begin{array}{l}19 \\
(1 \mathrm{RCT})\end{array}$ & $\begin{array}{l}\oplus \ominus \ominus \ominus \\
\text { VERY LOW } 12\end{array}$ & Remission was defined as a CDAI score $\leq 150$ \\
\hline $\begin{array}{l}\text { Proportion of patients } \\
\text { achieving clinical re- } \\
\text { sponse }\end{array}$ & Not reported & & & & & This outcome was not reported \\
\hline $\begin{array}{l}\mathrm{CRP}(\mathrm{mg} / \mathrm{dL}) \text { at end of } \\
\text { study }\end{array}$ & Not reported & & & & & This outcome was not reported \\
\hline Quality of life & Not reported & & & & & This outcome was not reported \\
\hline $\begin{array}{l}\text { Adverse events } \\
\text { Follow-up: } 8 \text { weeks }\end{array}$ & See comments & & & & & $\begin{array}{l}\text { Adverse events were rated on a scale from } \\
\text { one to seven and included headache, sleepi- } \\
\text { ness, nausea and dizziness } \\
\text { The proportion of participants in each group } \\
\text { who had an adverse event was not reported }\end{array}$ \\
\hline $\begin{array}{l}\text { Serious adverse events } \\
\text { Follow-up: } 8 \text { weeks }\end{array}$ & 111 per 1,000 & $\begin{array}{l}100 \text { per } 1,000 \\
\text { ( } 8 \text { to } 1,000)\end{array}$ & $\begin{array}{l}\text { RR } 0.90 \\
\text { (0.07 to } 12.38)\end{array}$ & $\begin{array}{l}19 \\
(1 \mathrm{RCT})\end{array}$ & $\begin{array}{l}\oplus \ominus \ominus \ominus \\
\text { VERY LOW } 13\end{array}$ & $\begin{array}{l}\text { There was one serious adverse event in each } \\
\text { group. Both were worsening Crohn's disease } \\
\text { that required rescue intervention }\end{array}$ \\
\hline $\begin{array}{l}\text { Withdrawal due to ad- } \\
\text { verse events }\end{array}$ & Not reported & & & & & This outcome was not reported \\
\hline
\end{tabular}

${ }^{*}$ The risk in the intervention group (and its 95\% confidence interval) is based on the assumed risk in the comparison group and the relative effect of the intervention (and its $95 \% \mathrm{Cl}$ ).

Cl: Confidence interval; RR: Risk ratio; OR: Odds ratio;

\section{GRADE Working Group grades of evidence}

High certainty: We are very confident that the true effect lies close to that of the estimate of the effect

Moderate certainty: We are moderately confident in the effect estimate: The true effect is likely to be close to the estimate of the effect, but there is a possibility that it is substantially different

Low certainty: Our confidence in the effect estimate is limited: The true effect may be substantially different from the estimate of the effect

Very low certainty: We have very little confidence in the effect estimate: The true effect is likely to be substantially different from the estimate of effect

${ }^{1}$ Downgraded one level due to high risk of bias for other bias (60\% of cannabis participants were smokers compared to none of the placebo participants) 


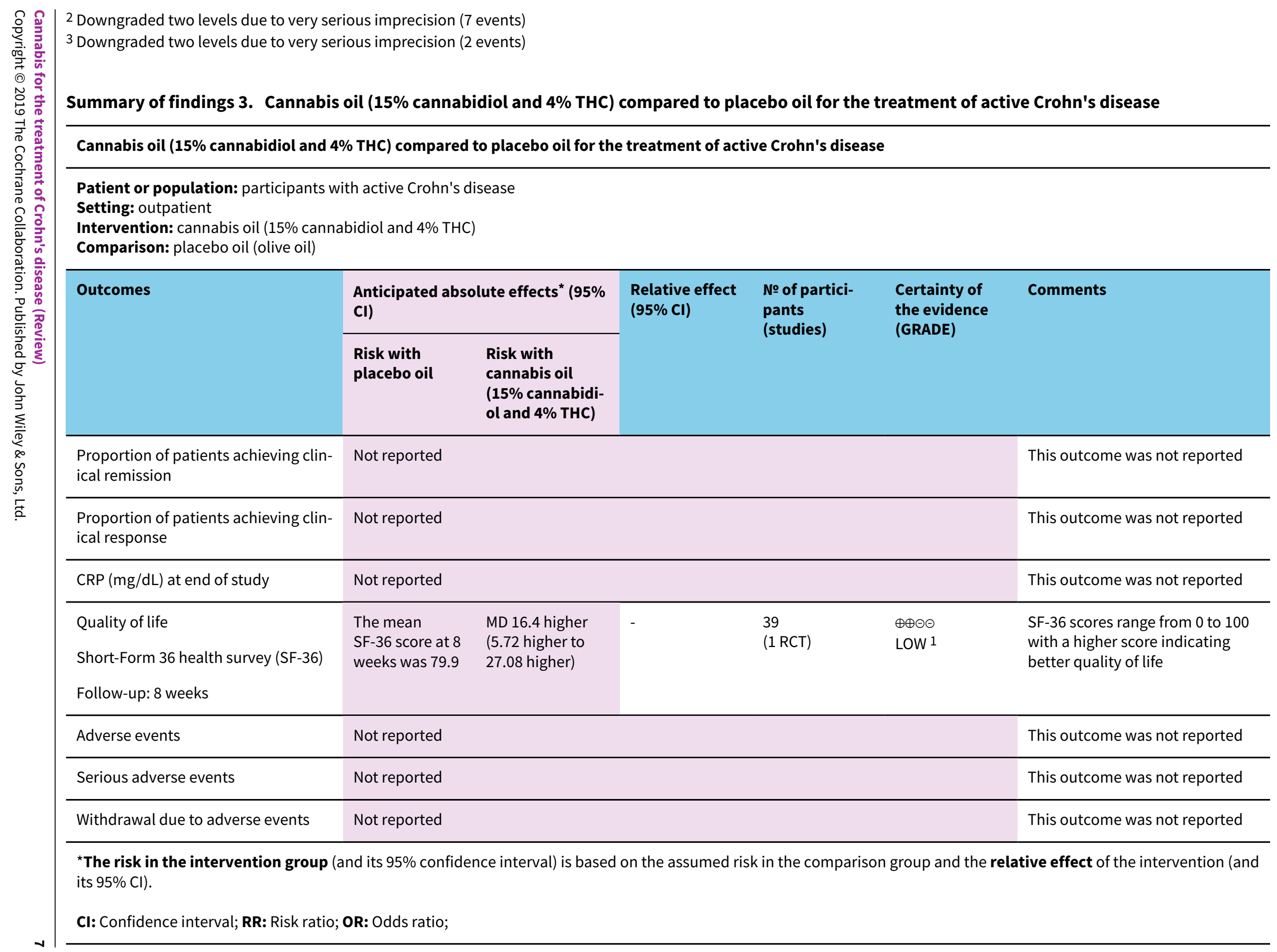

The risk in the intervention group (and its $95 \%$ confidence interval) is based on the assumed risk in the comparison group and the relative effect of the intervention (and

CI: Confidence interval; RR: Risk ratio; OR: Odds ratio; 


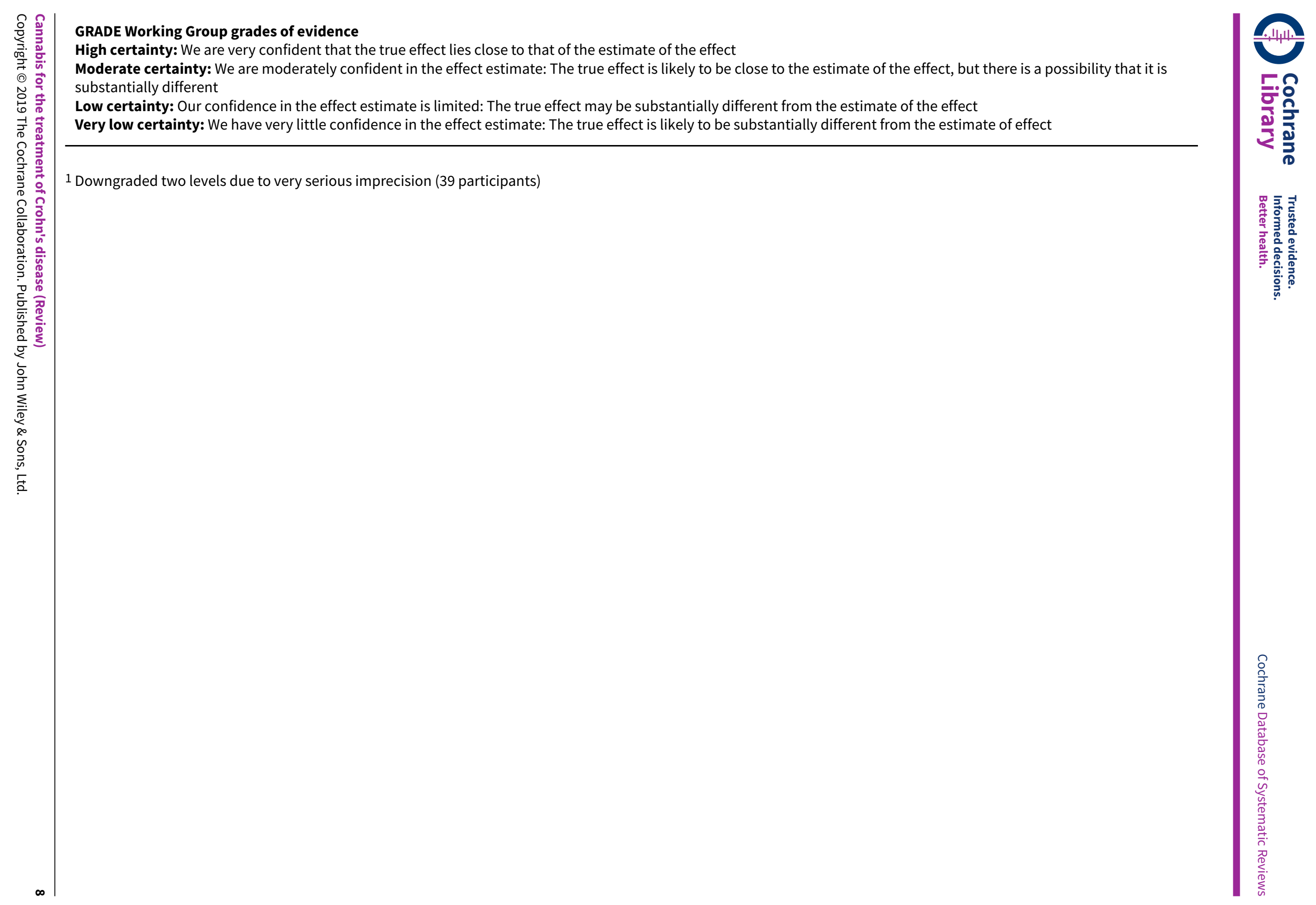




\section{B A C K G R O U N D}

Cannabis is a widely used recreational drug which alters sensory perception and causes euphoria (Tibirica 2010). It has been promoted as a treatment for a variety of diseases such as cancer, glaucoma and autoimmune diseases (Hill 2015). Cannabis has also been hypothesized to improve disease activity in Crohn's disease via modulation of the endocannabinoid system (Tibirica 2010). The endocannabinoid system has been shown to help regulate brain function and the immune system (Klein 2006).

Studies have found a higher prevalence of cannabis use in people with IBD who claim it relieves symptoms such as abdominal pain, diarrhoea, and reduced appetite (Lal 2011; Weiss 2015). It is unclear if this is due to the known psychotropic effects of cannabis such as analgesia and euphoria or if it is related to anti-inflammatory effects demonstrated in recent studies and experimental animal models (Hasenoehrl 2016; Klein 2006; Singh 2012). There is also evidence that cannabis use in people with Crohn's disease has potential for harm. Cannabis has been associated with higher risk of surgery in people with Crohn's disease (Storr 2014). Cannabinoids have been associated with an increased risk of transient adverse events including weakness, dizziness, and diarrhea (Whiting 2015). Despite these conflicting data, physicians are often asked to prescribe cannabis in the context of a rapidly growing medical cannabis industry (Fletcher 2013).

There were no placebo-controlled trials evaluating the use of cannabis in people with IBD until the first randomized, prospective, placebo-controlled trial was published in 2013 (Naftali 2013). This study raised important questions regarding the exact role of cannabis in treating people with Crohn's disease: Does cannabis lead to symptomatic improvement only or does it also objectively reduce inflammation? Is cannabis safe when used by people with Crohn's disease?

\section{Description of the condition}

Crohn's disease (CD) is a chronic immune-mediated condition of transmural inflammation in the gastrointestinal tract. $C D$ is associated with significant morbidity and decreased quality of life (Lahat 2012; Rubin 2004). In North America, the prevalence of CD is estimated to range from 26 to 199 cases per 100,000 person-years (Friedman 2012).

$C D$ can affect anywhere from the mouth to the perianal area. The pathophysiology of this condition is multifactorial and people may have a genetic predisposition (Friedman 2012). CD is thought to arise from a dysregulated immune response towards commensal microbiota and dietary contents in the gastrointestinal tract (Friedman 2012). This leads to an inappropriate inflammatory cascade of activated $T$ cells secreting excessive pro-inflammatory cytokines such as interleukin-1 (IL-1), IL-6, and tumor necrosis factor-alpha (TNF- $\alpha$ ) (Friedman 2012). This results in damage to previously healthy tissues.

CD is characterized by periods of relapse and remission (Friedman 2012). Symptoms may include low grade fevers, malaise, diarrhea, crampy abdominal pain, or hematochezia (Friedman 2012). The site of inflammation influences the symptoms. Complications of $\mathrm{CD}$ include fistula and abscess formation, perforations and fibrotic strictures (Friedman 2012; Lahat 2012).
Usual treatment options for CD include anti-inflammatory and immunosuppressant agents (Friedman 2012). Commonly used drugs are aminosalicylates, sulfasalazine, corticosteroids, thiopurine drugs, methotrexate and biologic therapies such as antiTNF- $\alpha$ agents (Friedman 2012). Management includes control of acute exacerbations, induction of remission, and maintenance of remission.

\section{Description of the intervention}

Cannabis sativa consists of numerous compounds called cannabinoids, of which delta 9-tetrahydrocannabinol (THC) is the main psychotropic component (Klein 2006). Many natural and synthetic cannabinoids have been found and studied including cannabidiol, cannabinol, cannabigerol, and dronabinol (Klein 2006). Some of these cannabinoids are psychoactive, whereas others are not (Klein 2006). Multiple experimental animal models have shown anti-inflammatory properties of various cannabinoids (Klein 2006).

\section{How the intervention might work}

The endocannabinoid system helps regulate the central nervous sytem, peripheral tissues, and multiple immune cells (Tibirica 2010). This system consists of cannabinoid (CB) receptors 1 and 2 , several endogenous ligands called 'endocannabinoids', and associated enzymes (Hasenoehrl 2016; Klein 2006). Multiple studies have shown that the endocannabinoid system helps control physiologic functions of the gut including motility, secretion and epithelial barrier integrity (Coutts 1998; Hasenoehrl 2016; Pinto 2002; Vianna 2012). This makes the endocannabinoid system a potential therapeutic target for gastrointestinal diseases. Cannabis and cannabinoids appear to influence this system via CB1 and CB2 receptors and other mechanisms (Hasenoehrl 2016; Klein 2006).

CB1 receptors are widely expressed in the gastrointestinal tract, central nervous system and peripheral tissues such as blood vessels (Hasenoehrl 2016; Klein 2006). In the GI tract, the CB1 receptors are found in the enteric nervous system, the epithelial lining, plasma cells, and smooth muscle cells of blood vessels (Hasenoehrl 2016). CB1 receptor activation may reduce gastric emptying, intestinal transit time, as well as reduce colonic propulsion (Pinto 2002). The brain-gut axis also influences motility and $C B 1$ receptors in the vagus nerve are part of normal motility (Vianna 2012). CB1 receptors modulate the release of multiple neurotransmitters in the central nervous system causing central effects such as a reduction in pain and nausea (Klein 2006; Tibirica 2010). Activation of the CB1 receptor may enhance epithelial wound closure in the colon (Wright 2005). There is also evidence that upregulation of $C B 1$ receptors and activation of $\mathrm{CB} 1$ receptors physiologically protects the colon during excessive inflammation in the colon (Massa 2004).

CB2 receptors are mainly expressed in immune cells, myenteric plexus neurons, and in epithelial cells during ulcerative colitis (Hasenoehrl 2016; Klein 2006; Marquez 2009). CB2 receptors are expressed on immune cells such B-cells, NK cells and macrophages (Klein 2006). CB2 activation leads to T-cell apoptosis and decreased proliferation in colitis (Singh 2012). CB2 activation also decreases the recruitment of neutrophils, $T$ cells and macrophages to the inflamed colon (Singh 2012).

Other receptors in the $\mathrm{GI}$ tract have been found to be endocannabinoid-responsive through mechanisms separate from 
CB1 and CB2 receptors (Hasenoehrl 2016). These include the peroxisome proliferator-activated receptor alpha, the G-protein coupled receptor 55, and transient receptor potential cation channel subfamily V member 1 (Hasenoehrl 2016). Cannabinoids also help modulate chemokine and cytokine release (Klein 2006).

\section{Why it is important to do this review}

This review was undertaken to evaluate the strength of evidence for the use of cannabis and cannabinoids as treatment for CD. It will help clarify if this therapy leads to objective physiological improvement beyond subjective and psychotropic scores. Further, we hope to evaluate various modes of consumption and assess for adverse effects.

\section{O B J E C T IVES}

The primary objective was to assess the efficacy and safety of cannabis for induction and maintenance of remission in people with Crohn's disease.

\section{METHODS}

\section{Criteria for considering studies for this review}

\section{Types of studies}

Randomized controlled intervention trials were considered for inclusion. Studies published as abstracts were only included if the authors could be reached for further information to allow for evaluation of quality and main outcomes.

\section{Types of participants}

Adults ( $\geq 18$ years of age) with Crohn's disease (as defined by the included studies) were considered for inclusion. Clinical remission or quiescent disease was defined by the Crohn's Disease Activity Index (CDAI). Participants with active (e.g. CDAI > 150) or quiescent disease (defined as mild or absent symptoms prior to entering the study or by a CDAI $\leq 150$ ) were included. People with surgicallyinduced remission were excluded.

\section{Types of interventions}

Studies comparing any form of cannabis or its cannabinoid derivatives (natural or synthetic) to placebo or an active therapy for Crohn's disease were included. We also included studies that assessed different cannabis or cannabinoid doses. An attempt was made to analyze dose response if data were available.

\section{Types of outcome measures}

\section{Primary outcomes}

The primary outcome was remission at study endpoint for induction of remission studies (as defined by a CDAI $\leq 150$ ) and relapse (e.g. CDAI > 150) at study endpoint for maintenance studies. Any validated scoring system such as the CDAI or Disease Activity Score (DAS) was included.

\section{Secondary outcomes}

Secondary outcomes included:

1. Clinical response;

2. Endoscopic remission;
3. Endoscopic improvement;

4. Histological response;

5. Quality of life;

6. CRP and fecal calprotectin measurements;

7. Adverse events;

8. Serious adverse events;

9. Withdrawal due to adverse events; and

10. Cannabis dependence and withdrawal effects.

\section{Search methods for identification of studies}

\section{Electronic searches}

We searched the following databases from inception up to 17 October 2018: MEDLINE, Embase, AMED (Allied \& Alternative Medicine), PsychINFO, the Cochrane IBD Group Specialized Register, CENTRAL, ClinicalTrials.Gov, and the European Clinical Trials Register.

We searched abstracts from major gastroenterological meetings to identify research published in abstract form. We also contacted authors in this field for upcoming publications. The electronic search strategy is reported in Appendix 1.

\section{Searching other resources}

Conference proceedings were searched to identify studies published in abstract form. We also searched the references of applicable studies and systematic reviews to identify additional studies. We searched ClinicalTrials.gov and the EU Clinical Trials Register to identify ongoing studies.

\section{Data collection and analysis}

\section{Selection of studies}

Study papers and abstracts were identified by the literature search and reviewed. Two authors (TK and NC) independently screened the search results to identify potentially relevant studies for full text evaluation. The studies selected for full text review were independently assessed by two authors (TK and NC) and consensus for study inclusion and exclusion was reached through discussion. Any conflicts regarding inclusion or exclusion were resolved through discussion and by consultation with a third author (JKM) as necessary. Studies published in abstract form were only be included if the authors could be reached for further information.

\section{Data extraction and management}

Two authors (TK and NC) independently extracted the outcome data of interest from each study. Any conflicts were resolved by discussion and consensus or by consultation with a third author (JKM) as necessary. If data were missing or unclear, the study authors were contacted for clarification.

Other information extracted from the studies included:

a. Study characteristics and design;

b. Characteristics of participants; 
c. Inclusion and exclusion criteria;

d. Interventions; and

e. Outcomes scoring methods.

\section{Assessment of risk of bias in included studies}

Two authors (TK and NC) independently assessed the methodological quality of included studies using the Cochrane risk of bias tool (Higgins 2011a). Any conflicts were resolved by discussion and consensus or by consultation with a third author (JKM) as necessary. Items assessed included:

1. Random sequence generation;

2. Allocation sequence concealment;

3. Blinding of participants, personnel and assessment of outcome;

4. Incomplete outcome data;

5. Selective outcome reporting; and

6. Other potential sources of bias.

Each category was evaluated as low, high or unclear risk. Judgment justification was provided in the Characteristics of included studies section of the review.

\section{GRADE Analysis}

The overall quality of the evidence supporting the primary outcome and selected secondary outcomes was evaluated using the GRADE criteria (Guyatt 2008; Schünemann 2011). Using this approach, outcome data were rated high, moderate, low or very low certainty. Outcome data from randomized controlled trials begins as high certainty, but could be downgraded based on several criteria. These criteria included:

1. Risk of bias from the studies;

2. Indirect evidence (by comparison, population, setting);

3. Inconsistency (i.e. unexplained heterogeneity);

4. Imprecision in data (i.e. few events and wide confidence intervals); and

5. Likelihood of publication bias.

\section{Measures of treatment effect}

For dichotomous outcomes, we calculated the risk ratio (RR) and corresponding 95\% confidence interval $(\mathrm{Cl})$. For continuous outcomes, we calculated the mean difference (MD) and corresponding $95 \% \mathrm{Cl}$.

\section{Unit of analysis issues}

For multi-arm trials with a single placebo group and two treatment dose groups, we planned to split the placebo group in half to avoid a unit of analysis error (Higgins 2011b). To avoid potential carry-over effects, we planned to only include the first part of the study (i.e. before the cross-over) for any cross-over studies (Higgins 2011b).
For studies where events reoccurred, we included the proportion of participants who experienced at least one event (i.e. the first event). When there were repeated observations on participants, we used the primary endpoint defined by the study. We did not find study designs applicable to cannabis in Crohn's disease where multiple treatment attempts were used. We did not find any available cluster-randomized studies.

\section{Dealing with missing data}

Data were analyzed on an intention-to-treat basis. Studies were evaluated for missing data and where explanations were not provided, the patient outcome was considered to be a treatment failure. For dichotomous outcomes, we dealt with missing data by treating missing participants as treatment failures. We counted failures as a relapse for maintenance studies and as failure to enter remission for induction studies.

We conducted an available case analysis for missing continuous outcomes. For missing standard deviations of continuous outcomes, we imputed standard deviations where reasonably possible. Sensitivity analysis was used to assess the impact of any imputation.

\section{Assessment of heterogeneity}

We planned to assess statistical heterogeneity using the $\mathrm{Chi}^{2}$ test and $\mathrm{I}^{2}$ statistic. For the $\mathrm{Chi}^{2}$ test, a $\mathrm{P}$ value of less than 0.1 would be considered statistically significant. We planned to use the $1^{2}$ statistic to assess the degree of statistical heterogeneity. We planned to investigate heterogeneity by visually inspecting the forest plots to identify outliers. If outliers were identified, we would conduct sensitivity analysis to explore potential explanations for the heterogeneity. If significant heterogeneity was identified, a random-effects model would be used. We planned to not pool data for meta-analysis when a high degree of heterogeneity was detected (e.g. $\left.\left.\right|^{2}>75 \%\right)$.

\section{Assessment of reporting biases}

We assessed selective reporting by comparing outcomes prespecified in study protocols to those reported in study manuscripts. If protocols were not available for the included studies, we assessed reporting bias by comparing the outcomes specified in the methods section of the manuscript to those reported in the results section. If there were more than 10 included studies in a pooled analysis, we planned to investigated publication bias by constructing funnel plots (Egger 1997).

\section{Data synthesis}

We planned to combine data from individual trials when the interventions, patient groups and outcomes were sufficiently similar (determined by consensus). When pooling studies was not possible, we narratively summarized the results of individual trials. For dichotomous outcomes, we planned to calculate the pooled RR and $95 \% \mathrm{Cl}$ using a fixed-effect model. For continuous outcomes, we planned to calculate the pooled MD and corresponding 95\% $\mathrm{Cl}$. For continuous outcomes that utilized different scales to measure the same underlying construct, we planned to calculate the standardized mean difference (SMD) and corresponding 95\% $\mathrm{Cl}$. 


\section{Subgroup analysis and investigation of heterogeneity}

We attempted to perform subgroup analyses by dose and formula (e.g. based on dose of THC, dose of cannabidiol , or combination formula) when the data allowed for such comparisons. Other subgroup analyses considered included an effect based on disease location, cigarette smoking status, history of biologic therapy and failure of biologic therapy.

\section{Sensitivity analysis}

We planned to perform a sensitivity analysis based on risk of bias. However, there were no studies were pooled for analysis because of differences in the interventions.

\section{RES U L T S}

\section{Description of studies}

\section{Results of the search}

A literature search conducted on 17 October 2018 identified 91 studies. After duplicates were removed, a total of 63 studies remained for screening. Fifty-six of these studies were not applicable. Seven studies remained for full-text review. One study was excluded (Naftali 2013b). Five reports of three studies (93 participants) met the inclusion criteria and were included in the review (See Figure 1). One ongoing study was also identified (NCT03467620).

\section{Figure 1. Flow diagram.}

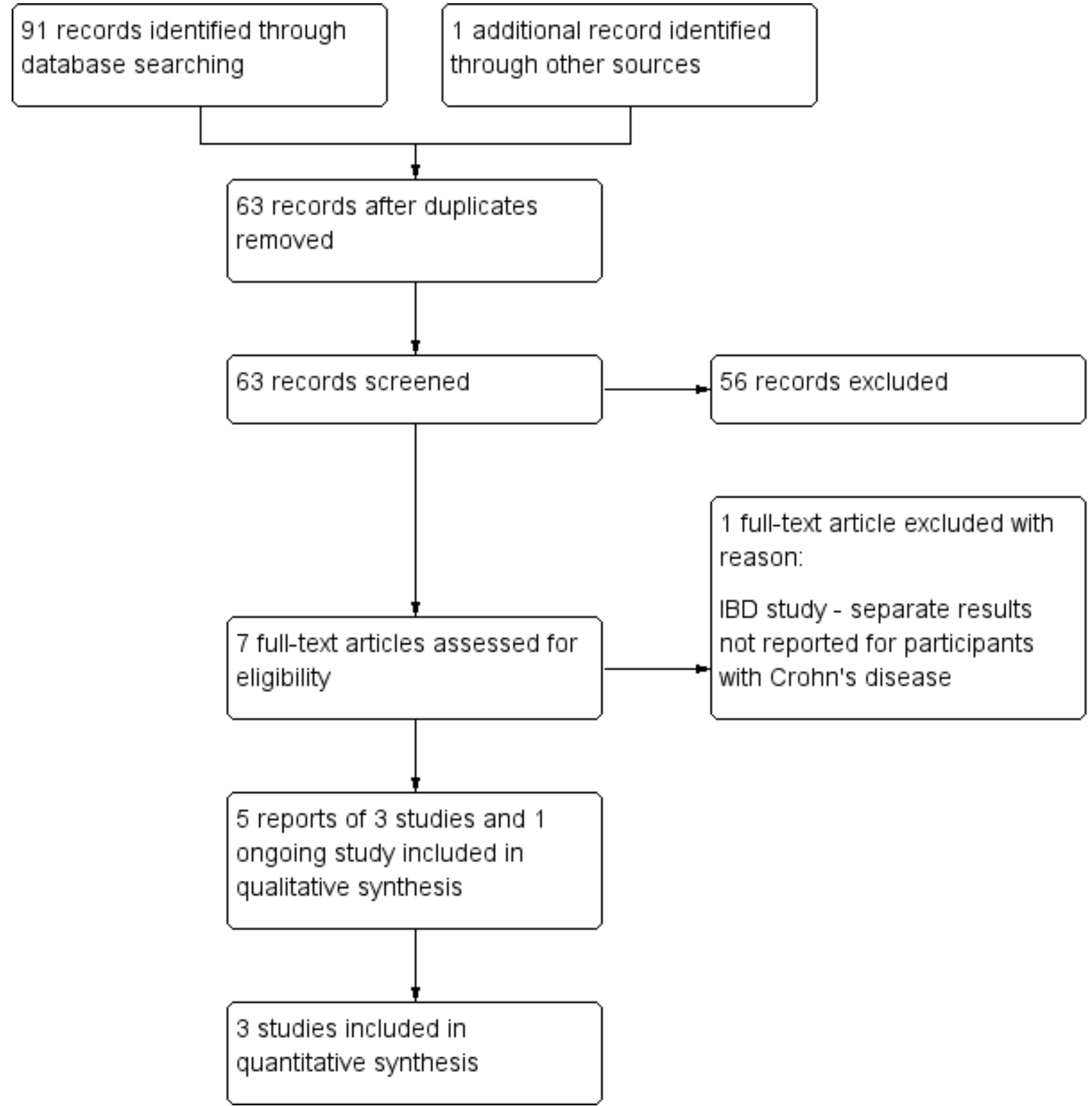




\section{Included studies}

Naftali 2013a was a randomized, single-centre, double-blind, placebo-controlled trial. The purpose of the study was to determine whether cannabis can induce remission in participants with active Crohn's disease. Participants were given either cannabis cigarettes containing $115 \mathrm{mg}$ of THC twice daily or placebo cigarettes composed of cannabis flowers from which the THC had been extracted. Participants were treated for eight weeks. Twenty-two people were randomized, but 21 participants were studied (cannabis $\mathrm{n}=11$; placebo $\mathrm{n}=10$ ). One person declined participation after signing consent, but before receiving any study drugs. Inclusion criteria were an established diagnosis of Crohn's disease, at least 20 years of age, and active Crohn's disease (with a calculated CDAl score between 200 and 450 points) at study entry. All participants had failed at least one form of medical treatment for the disease including mesalamine, corticosteroids, thiopurines, methotrexate, or anti-TNF- $\alpha$. Anti-TNF- $\alpha$ failure was declared after at least four doses. Participants receiving corticosteroids had to be receiving a stable dose for at least one month prior to study entry, and participants receiving thiopurines had to be receiving a stable dose for at least three months prior to entry. Participants were followed at weeks $0,2,8$, and 10 (2 weeks after treatment done). The primary outcome was induction of remission, defined as a CDAI score of 150 or less after 8 weeks of cannabis treatment. Secondary outcomes included response rate, defined as a 100-point reduction of CDAl from baseline, a reduction of at least $0.5 \mathrm{mg}$ in C-reactive protein (CRP), or improvement in quality of life of at least 50 points, as measured by the Short-Form 36 (SF-36) health survey. Adverse effects were assessed by questionnaire and severity was assessed on a scale from one to seven, with one meaning no symptoms and seven corresponding with severe symptoms.

Naftali 2017a was a randomized, single-centre, double-blind, placebo-controlled trial. The purpose of the study was to assess the effects of cannabidiol in participants with active Crohn's disease. Participants were given either $2 \mathrm{ml}$ twice daily of cannabis oil at a concentration of $5 \mathrm{mg} / \mathrm{ml}$ (i.e. $20 \mathrm{mg} /$ day or approximately $5 \%$ cannabidiol) or placebo containing pure olive oil $2 \mathrm{ml}$ twice daily. Twenty-one participants were recruited, one withdrew consent before any consumption of the study drug and one was withdrawn due to colitis. Nineteen participants completed the study. Participants were at least 20 years of age, had active Crohn's disease with a calculated CDAl score between 200 and 450 points, and received at least one form of medical treatment for Crohn's disease with no effect. Previous treatments included mesalamine, corticosteroids, thiopurines, methotrexate, or antiTNF- $\alpha$. Participants receiving corticosteroids had to be on a stable dose for at least one month. Participants receiving thiopurines had to be on a stable dose for at least three months, and participants receiving anti-TNF- $\alpha$ had received at least four infusions before failure was declared. Participants were visited at weeks $0,2,8$, and 10 . The primary outcome was a reduction of 70 points in CDAI from week 0 to week 8 . Secondary outcomes included any adverse events within the time frame of eight weeks, ability to stop steroids in participants who were treated with steroids at the beginning of the study, and reduction in at least $1 \mathrm{mg} / \mathrm{dl}$ in the CRP level. Adverse effects were assessed by questionnaire as described for Naftali 2013a

Naftali 2017b was an abstract presented at the International Association of Cannabis Medicine in September 2017. This study was sent to us by the first author. It is a randomized, doubleblind, placebo-controlled trial looking at the effect of cannabis on Crohn's disease. Participants were randomized to either cannabis oil ( $15 \%$ cannabidiol and $4 \%$ THC) or placebo oil for eight weeks of treatment. The cannabis oil group had 24 participants and the placebo oil group had 26 participants. Inclusion criteria were not specified. Outcomes included the CDAI, inflammatory markers and quality of life as measured by the Short-Form 36 (SF-36) health survey. These outcomes were assessed before, during and after treatment.

\section{Excluded studies}

Naftali 2013b was excluded because we were not able to acquire separate data for participants with Crohn's disease and ulcerative colitis. The study included 10 people with ulcerative colitis and 22 people with Crohn's disease.

\section{Risk of bias in included studies}

Bias was assessed using the Cochrane risk of bias tool. The risk of bias results are summarized in Figure 2. 
Figure 2. Risk of bias summary: review authors' judgements about each risk of bias item for each included study.

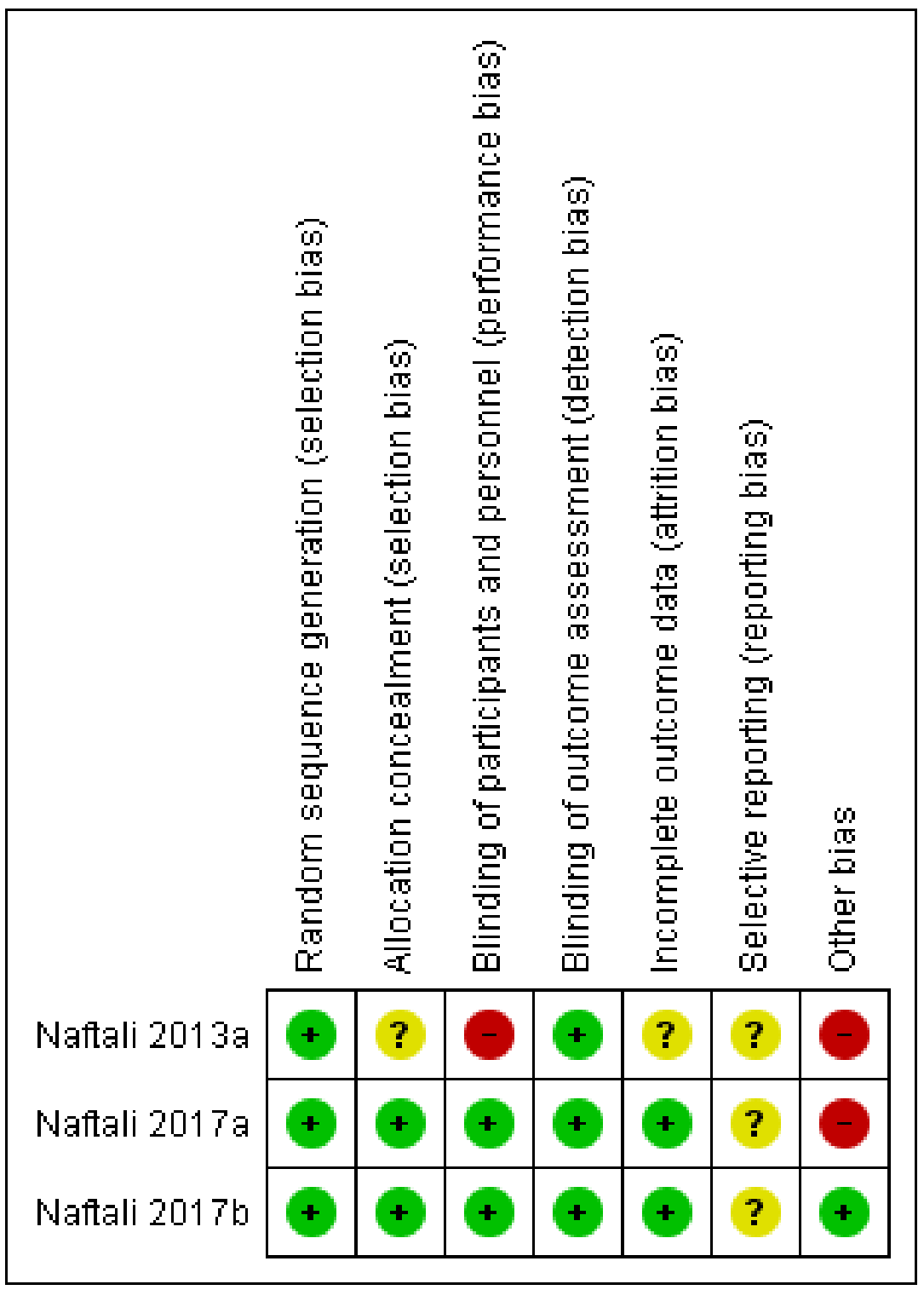

\section{Allocation}

Random sequence generation was rated as low risk of bias for all three studies given the use of the block randomization.

Allocation concealment was rated as unclear risk of bias for Naftali 2013a as the methods for allocation concealment were not described. Naftali 2017a and Naftali 2017b were rated as low risk of bias for allocation concealment. Both studies used sequentially numbered drug containers of identical appearance.

\section{Blinding}

Blinding was performed for both participants and investigators in all three studies. Both Naftali 2017a and Naftali 2017b used identical placebos and were rated as low risk of bias. However, blinding was not effective in Naftali 2013a due to the psychotropic effects of cannabis. Almost all participants were aware of their study allocation with the exception of two participants in the placebo group, before the end of the study. As a result we decided to rate Naftali 2013a as high risk of bias for blinding of participants. Outcome assessors were blinded in all three studies and this item was rated as low risk of bias.

\section{Incomplete outcome data}

Incomplete outcome data were rated as unclear for Naftali 2013a and low risk of bias for Naftali 2017a and . Naftali 2017b. There was a higher drop out rate in the placebo group of the Naftali 2013a study compared to the cannabis group (three placebo versus one cannabis). Alternatively, there were no drop outs for the Naftali 2017a and Naftali 2017b studies and therefore, incomplete outcome data was rated as low risk of bias.

\section{Selective reporting}

All three studies were rated as unclear risk of bias for selective reporting. The protocol for the Naftali 2013a study pre-specified the primary outcome as clinical response (reduction in CDAI of 70points from baseline). In the manuscript the authors reported on 
clinical remission $(C D A I \leq 150)$ as the primary outcome. We note that clinical remission is a more stringent outcome than clinical response and that this is not strong evidence of selective reporting to bias the results in favour of the intervention. The study protocol also included change in IL-10, IL-2, and TGF beta as secondary outcomes and these outcomes were not reported in the final study manuscript. The protocol for the Naftali 2017a study also prespecified the primary outcome as clinical response (reduction in CDAI of 70-points from baseline). In the manuscript the authors reported on clinical remission $(\mathrm{CDAl} \leq 150)$ as the primary outcome. Again we note that clinical remission is a more stringent outcome than clinical response and that this is not strong evidence of selective reporting to bias the results in favour of the intervention. The study protocol also included a reduction of at least $1 \mathrm{mg} / \mathrm{dL}$ in the serum CRP levels and this was not reported in the final manuscript. The Naftali 2017b was published as an abstract. The abstract reported on a pre-specified secondary outcome (quality of life) but did not report on the pre-specified primary outcome from the study protocol (clinical response defined by a 100-point reduction in CDAI) or other pre-specified outcomes (e.g. clinical remission). However, these outcomes could be reported on in the full study manuscript.

\section{Other potential sources of bias}

Naftali 2013a was rated as high risk of bias for other potential sources of bias because participants in the cannabis participants were significantly older than participants in the placebo group. Naftali 2017a was rated as high risk of bias because there were significantly more smokers in the cannabis oil group than the placebo group. Sixty per cent of the cannabis oil group smoked compared to none of the placebo group. The Naftali 2017b study was rated as low risk of bias..

\section{Effects of interventions}

See: Summary of findings for the main comparison Cannabis cigarettes (115 mg THC) compared to placebo cigarettes for the treatment of active Crohn's disease; Summary of findings 2 Cannabis oil ( $5 \%$ cannabidiol sublingual oil) compared to placebo oil for the treatment of active Crohn's disease; Summary of findings 3 Cannabis oil (15\% cannabidiol and 4\% THC) compared to placebo oil for the treatment of active Crohn's disease

Data from the three included studies were not pooled due to the different routes of administration and formula composition for the two studies that used cannabis oil. The Naftali 2013a study participants took $115 \mathrm{mg}$ of THC in the form of cigarettes (twice daily) and the Naftali 2017a study participants took cannabis oil at a concentration of $5 \%$ cannabidiol. The Naftali $2017 \mathrm{~b}$ study utilized cannabis oil at a concentration of $15 \%$ cannabidiol and $4 \%$ THC.

\section{Cannabis cigarettes (115 $\mathrm{mg}$ THC) versus placebo cigarettes at 8 weeks:}

Clinical remission rates at eight weeks were higher in the cannabis cigarettes group compared to placebo cigarettes (Naftali 2013a). Clinical remission was reported in $45.5 \%(5 / 11)$ of participants in the treatment group compared to $10 \%(1 / 10)$ of participants in the placebo group (RR 4.55, $95 \% \mathrm{Cl} 0.63$ to 32.56; very low certainty evidence). Clinical response was reported in $90.9 \%(10 / 11)$ of participants in the treatment group compared to $40 \%(4 / 10)$ of participants in the placebo group (RR $2.27,95 \% \mathrm{Cl} 1.04$ to 4.97 ; very low certainty evidence). There was no difference in serum
CRP levels measured at the end of the study. A decrease in CRP of more than $0.5 \mathrm{mg} / \mathrm{dL}$ from week 0 to week 8 was found in $27 \%(3 / 11)$ of participants in the treatment group compared to $20 \%(2 / 10)$ of participants in the placebo group (RR $1.36,95 \% \mathrm{Cl}$ 0.28 to 6.56 ; low certainty evidence). There was an increase in the quality of life scores in the treatment group compared to the placebo group. There was an increase of 28 points in the treatment group from baseline to week 8, compared to a difference of 5 points in the placebo group from baseline to week 8 . None of the participants experienced difficulty or withdrawal symptoms when they stopped the cannabis treatment after eight weeks. We acquired the prevalence of adverse effects from the author, and the cannabis group had more adverse events compared to the placebo. Eighty-two per cent (9/11) of participants in the cannabis group had an adverse event compared to $20 \%(2 / 10)$ of placebo participants (RR $4.09,95 \% \mathrm{Cl} 1.15$ to 14.57 ; very low certainty evidence). However, these adverse events were considered to be mild in nature and included sleepiness, nausea, difficulty with concentration, memory loss, confusion and dizziness. Participants in the cannabis group reported improvements in pain, appetite and satisfaction. Endoscopic remission, endoscopic response, histological response, serious adverse events and withdrawal due to adverse events were not reported in this study.

\section{Cannabis oil ( $5 \%$ cannabidiol sublingual oil) versus placebo oil} at 8 weeks:

There was no difference in remission rates at eight weeks in the small study $(n=19)$ that compared cannabis oil ( $5 \%$ cannabidiol sublingual oil) to placebo oil (Naftali 2017a). Clinical remission was reported in $40 \%(4 / 10)$ of participants in the cannabis oil group compared to $33.3 \%(3 / 9)$ of participants in the placebo group (RR $1.20,95 \% \mathrm{Cl} 0.36$ to 3.97 ; very low certainty evidence). There was no difference in the proportion of participants who had a serious adverse event. Ten per cent $(1 / 10)$ of participants in the cannabis oil group had a serious adverse event compared to $11 \%$ (1/9) of placebo participants (RR $0.90,95 \% \mathrm{Cl} 0.07$ to 12.38 ; very low certainty evidence). In both cases the serious adverse event was worsening Crohn's disease that required rescue intervention. The participants did not report any withdrawal symptoms when treatment was stopped. Although the study protocol stated they were going to assess clinical response (reduction of 70 points in the CDAl from week 0 to 8 ) as the primary outcome, and reduction in CRP level, the final data for these outcomes were not reported. Additionally, endoscopic remission, endoscopic response and histological response were not assessed in this study. Adverse effects were rated on a scale from one to seven and included headache, sleepiness, nausea and dizziness. The authors reported that adverse effects did not differ between the cannabis oil and placebo groups.

\section{Cannabis oil ( $15 \%$ cannabidiol and $4 \%$ THC) versus placebo oil at 8 weeks:}

The small study ( $\mathrm{n}=39$ ) comparing cannabis oil ( $15 \%$ cannabidiol and $4 \% \mathrm{THC}$ ) to placebo oil found differences in CDAl scores and quality of life scores as measured by the SF-36 instrument. The mean quality of life score after 8 weeks of treatment was 96.3 in the cannabis oil group compared to 79.9 in the placebo group (MD $16.40,95 \% \mathrm{Cl} 5.72$ to 27.08 , low certainty evidence). After 8 weeks of treatment, the mean CDAI score was 118.6 in the cannabis oil group compared to 212.6 in the placebo group (MD $-94.00,95 \% \mathrm{Cl}-148.86$ 
to -39.14 , low certainty evidence). The abstract did not report on any other outcomes.

\section{DISCUSSION}

\section{Summary of main results}

This systematic review included three small randomized controlled trials (93 participants) that evaluated the efficacy and safety of cannabis and cannabis oil (cannabidiol) in Crohn's disease. Overall, there were sparse data and heterogenous outcomes. Each study used a different dose of cannabis or cannabidiol formula. Naftali 2013a compared cannabis cigarettes (115 mg THC) to placebo cigarettes. Naftali 2017 a compared cannabis oil composed of $5 \%$ cannabidiol sublingual oil to a placebo oil. Naftali 2017b compared cannabis oil composed of $15 \%$ cannabidiol and $4 \%$ THC to a placebo oil. We were only able to extract limited data on quality of life (SF-36) and CDAl scores from this study. None of the studies were pooled due to the different routes of administration and cannabidiol formulas. No studies were identified that assessed cannabis or cannabis oil therapy in people with quiescent Crohn's disease.

In the Naftali 2013a study, clinical remission and response rates were higher in the cannabis cigarette group than the placebo cigarette group at eight weeks. This study found no difference in serum CRP levels after eight weeks of treatment. Participants in the cannabis group were more likely than placebo participants to experience an adverse event. However, these adverse events were considered to be mild in nature and included sleepiness, nausea, difficulty with concentration, memory loss, confusion and dizziness. Participants in the cannabis group reported improvements in pain, appetite and satisfaction with treatment. These results should be interpreted with caution as the GRADE analysis indicated that the overall certainty of the evidence supporting these results was very low due to sparse data and high risk of bias. Thus, we are uncertain about the effects of cannabis cigarettes on Crohn's disease. Further research is needed before any strong conclusions can be drawn on the efficacy and safety of cannabis cigarettes in Crohn's disease.

The Naftali 2017a study found no difference in clinical remission rates at eight weeks or serious adverse events. One serious adverse event was reported in each group. In both cases the serious adverse event was worsening Crohn's disease that required rescue intervention. Reported adverse events included headache, sleepiness, nausea and dizziness. The GRADE analysis indicated that the overall certainty of the evidence supporting these results was very low due to sparse data and high risk of bias. Thus, we are uncertain about the effects of cannabis oil (5\% cannabidiol) on Crohn's disease. Further research is needed before any strong conclusions can be drawn on the efficacy and safety of cannabis oil ( $5 \%$ cannabidiol) in Crohn's disease.

Lastly, the Naftali 2017b study compared cannabis oil (15\% cannabidiol and $4 \%$ THC) to placebo. This study was presented as an abstract and only reported on quality of life and CDAI scores. Mean quality of life scores were higher in the cannabis oil group (96.3) compared to placebo (79.9). The mean difference between the cannabis oil and placebo groups was 16.4 points and this is likely to be a clinically meaningful improvement in health-related quality of life in people with Crohn's disease (Irvine 1994; Irvine 2008). However, the GRADE analysis indicated that the overall certainty of the evidence for this outcome was low due to due to serious imprecision. Further research is needed before any firm conclusions can be drawn about potential quality of life benefits with cannabis oil (15\% cannabidiol and 4\% THC) therapy in Crohn's disease. Mean CDAI scores were lower in cannabis oil participants (118.6) compared to placebo participants (212.6). Although, the difference in CDAI is clinically meaningful (Brant 1999; Feagan 2004), this result should be interpreted with caution given the small number of participants who were assessed. Further research is needed before any firm conclusions can be drawn about potential benefits of cannabis oil in terms of improved disease activity.

There are significant risks of bias with the included studies and a paucity of data on adverse events (short-term and long-term). The existing studies excluded people with a history of mental illness, drug abuse, or previous cannabis consumption, or if in their physician's judgement they might be vulnerable to drug addiction or mental instability (Naftali 2013a; Naftali 2017a). Hence, given the high prevalence of cannabis use and mental health disorders such as anxiety and depression in the Crohn's disease population, it is challenging to generalize the results of these small studies to all people with Crohn's disease.

We must weigh the possibility of small benefit of cannabis and cannabinoids in Crohn's disease against the well-established harms and concerns of cannabis including mental health related concerns (Triantafillidis 2013). Cannabis use is associated with increased emergency department visits in people with gastrointestinal diseases (Gubatan 2015).

Co-use of tobacco and cannabis is highly prevalent among cannabis users (Schauer 2016; Schauer 2017). Tobacco smoking in people with Crohn's disease leads to increased morbidity and smoking cessation improves outcomes (Johnson 2005). Further, there is concern that cannabis and tobacco are often combined in the same product (Schauer 2017). This is particularly worrisome in adolescents and young adults because of potential mental health symptoms (Ramo 2012). Mental health disorders such as anxiety and depression are prevalent among people with IBD and can negatively influence the course of IBD (Triantafillidis 2013). It is not known if cannabis smoking will increase concomitant tobacco use. People with Crohn's disease who use cannabis or cannabis oil may benefit from screening for tobacco use and counselling on smoking cessation. Close monitoring for adverse events in people with Crohn's disease who use cannabis may be beneficial given the lack of robust data and conversely, the presence of large body of data suggesting evidence of harm with cannabis use (Asbridge 2012; Gubatan 2015; Hackam 2015; Schauer 2016).

\section{Overall completeness and applicability of evidence}

This review included three small studies with a total of 93 participants, so completeness of evidence is a concern. More research is needed to be able to draw any firm conclusions about the efficacy and safety of cannabis in people with Crohn's disease. Although the results of this review may be applicable to persons with Crohn's disease there are some concerns with applicability because the included studies excluded people with a history of mental illness, drug abuse, or previous cannabis consumption. Both cannabis use and mental illness such as depression and anxiety are prevalent among people with IBD in North America (Hauser 2014; Weiss 2015). 


\section{Quality of the evidence}

The Naftali 2013a study was rated as high risk of bias for blinding of participants and other bias (cannabis participants were older than placebo participants). Although the authors took care to assign placebo participants to identical placebo cigarettes, the majority of participants were able to figure out which group they were assigned to due to the psychotropic effects of cannabis. The Naftali 2017a study was rated as high risk of bias due to other bias. Sixty per cent of cannabis participants were smokers compared to none of the placebo participants. The Naftali $2017 \mathrm{~b}$ study was rated as low risk of bias. Our assessment based on GRADE analyses suggests that the certainty of the evidence supporting the outcomes in this review is low to very low. As a result of this uncertainty no firm conclusions regarding the efficacy and safety of cannabis for Crohn's can be drawn.

\section{Potential biases in the review process}

We performed a comprehensive literature search to minimize bias related to study selection. Two authors (TK and NC) reviewed the studies for inclusion and exclusion, extracted data independently, and reviewed study quality. Limitations of this systematic review include a small number of studies with a small number of participants and sparse data. Two of the included studies were judged to be at high risk of bias (Naftali 2013a; Naftali 2017a). In addition, all three eligible studies were conducted by the same investigator (Naftali).

\section{Agreements and disagreements with other studies or reviews}

We found two systematic reviews that assessed the use of cannabis in Crohn's disease (Langhorst 2015; Volz 2016). Langhorst 2015 assessed all complementary and alternative medical treatments for inflammatory bowel disease and Volz 2016 assessed the use of cannabis in inflammatory bowel disease, irritable bowel syndrome and chronic pancreatitis. Both reviews included the Naftali 2013a study and both reviews had similar conclusions. Langhorst 2015 concluded that complementary and alternative therapies might be effective for the treatment of inflammatory bowel disease. Volz 2016 concluded that cannabis may be useful for symptom relief. Studies with higher methodological quality and larger numbers of participants are required to allow for more definitive conclusions on the efficacy and safety of cannabis for Crohn's disease.

\section{AUTHORS' CONCLUSIONS}

\section{Implications for practice}

The effects of cannabis and cannabis oil on Crohn's disease are uncertain. Thus no firm conclusions regarding the efficacy and safety of cannabis and cannabis oil in adults with active Crohn's disease can be drawn. There is no evidence for cannabis or cannabinoid use for maintenance of remission in Crohn's disease.

\section{Implications for research}

Further studies with larger numbers of participants are required to assess the potential benefits and harms of cannabis in Crohn's disease. Research from different investigator groups will be helpful to assess for reproducibility of results. Future studies should assess the effects of cannabis in people with both active and quiescent Crohn's disease. Different doses of cannabis and delivery modalities should be investigated. Future RCTs should more clearly assess adverse events. Long-term follow-up is needed to assess both self-reported and objective measurements of withdrawal, safety outcomes, consequences in terms of cognitive function, and capacity to function in activities of daily living while using cannabis.

\section{ACK N O WLEDGEMENTS}

Funding for the Cochrane IBD Group (May 1, 2017 - April 30, 2022) has been provided by Crohn's and Colitis Canada (CCC).

We would like to thank Dr. Timna Naftali for providing additional information on her studies. 


\section{R E F E R E N C E S}

\section{References to studies included in this review}

Naftali 2013a \{published and unpublished data\}

Naftali T, Bar-Lev L, Gabay G, Chowers Y, Dotan I, Bronshtein M, et al. Tetrahydrocannabinol (THC) rich medical cannabis induces clinical and biochemical improvement with a steroid sparing effect in active Crohn's disease. Gastroenterology 2012;1:S780.

* Naftali T, Bar-Lev Schleider L, Dotan I, Lansky EP, Sklerovsky Benjaminov F, Konikoff FM. Cannabis induces a clinical response in patients with Crohn's disease: a prospective placebo-controlled study. Clinical Gastroenterology and Hepatology 2013;11(10):1276-80.

\section{Naftali 2017a \{published and unpublished data\}}

Naftali T, Mechoulam R, Gabay G, Stein A, Bronshtein M, Mari A et al. Cannabidiol treatment does not effect active Crohn's disease. Gastroenterology 2013;1:S180.

* Naftali T, Mechulam R, Marii A, Gabay G, Stein A, Bronshtain M, et al. Low-dose cannabidiol is safe but not effective in the treatment for Crohn's Disease, a randomized controlled trial. Digestive Diseases and Sciences 2017;62:1615-20.

\section{Naftali 2017b \{published and unpublished data\}}

Naftali T, Schlieder LBL, Konikoff FM. The effect of cannabis on Crohn's Disease patients. International Association of Cannabis Medicine (IACM). 2017.

\section{References to studies excluded from this review}

Naftali 2013b \{published and unpublished data\}

Naftali T, Barlev L, Gabay G, Chowers Y, Dotan I, Stein A, et al. Tetrahydrocannabinol (THC) induces clinical and biochemical improvement with a steroid sparing effect in active inflammatory bowel disease. Journal of Crohn's and Colitis 2013;7(Supplement1):S153.

\section{References to ongoing studies}

NCT03467620 \{published data only\}

NCT03467620. Cannabidiol Usage as an Adjunct Therapy for Crohn's Disease [Oral Cannabidiol Capsule Usage as an Adjunct Therapy for Crohn's Disease: a Randomized, Placebo-controlled Study]. clinicaltrials.gov/ct2/show/NCT03467620 (accessed 17 October 2018)

\section{Additional references}

\section{Asbridge 2012}

Asbridge M, Hayden JA, Cartwright JL. Acute cannabis consumption and motor vehicle collision risk: systematic review of observational studies and meta-analysis. BMJ 2012;344:e536.

\section{Brant 1999}

Brant R, Sutherland L, Hilsden R. Examining the minimum important difference. Statistics in Medicine 1999;18(19):2593-603.

\section{Coutts 1998}

Coutts AA, Pertwee RG. Evidence that cannabinoid-induced inhibition of electrically evoked contractions of the myenteric plexus - longitudinal muscle preparation of guinea-pig small intestine can be modulated by $\mathrm{Ca} 2+$ and cAMP. Canadian Journal of Physiology and Pharmacology 1998;76:340-6.

\section{Egger 1997}

Egger M, Davey Smith G, Schneider M, Minder C. Bias in meta-analysis detected by a simple, graphical test. $B M J$ 1997;315:629-34.

\section{Feagan 2004}

Feagan BG. 5-ASA therapy for active Crohn's disease: old friends, old data, and a new conclusion. Clinical Gastroenterology and Hepatology 2004;2(5):376-8.

\section{Fletcher 2013}

Fletcher J. Marijuana is not a prescription medicine. Canadian Medical Association Journal 2013;185(5):369.

\section{Friedman 2012}

Friedman S, Blumberg RS. Chapter 295: Inflammatory Bowel Disease. Harrison's Principles of Internal Medicine. 18th Edition. The McGraw-Hill Companies, 2012.

\section{Gubatan 2015}

Gubatan J, Staller K, Barshop K, Kuo B. Cannabis abuse is increasing and associated with increased emergency department utilization in gastroenterology patients. Digestive Diseases and Sciences 2016;61:1844-52.

\section{Guyatt 2008}

Guyatt GH, Oxman AD, Vist GE, Kunz R, Falck-Ytter Y, AlonsoCoello $P$, et al. GRADE: an emerging consensus on rating quality of evidence and strength of recommendations. $B M J$ 2008;336(7650):924-6.

\section{Hackam 2015}

Hackam DG. Cannabis and stroke - systematic appraisal of case reports. Stroke 2015;46:852-6.

\section{Hasenoehrl 2016}

Hasenoehrl C, Taschler U, Storr M, Schicho R. The gastrointestinal tract - a central organ of cannabinoid signaling in health and disease. Journal of Neurogastroenterology and Motility 2016;28(12):1765-80.

\section{Hauser 2014}

Hauser W, Moser G, Klose P, Mikocka-Walus A. Psychosocial issues in evidence-based guidelines on inflammatory bowel diseases: A review. World Journal of Gastroenterology 2014;20(13):3663-71. 


\section{Higgins 2011a}

Higgins JPT, Altman DG, Sterne JAC (editors). Chapter 8: Assessing risk of bias in included studies. In: Higgins JPT, Green S editor(s). Cochrane Handbook for Systematic Reviews of Interventions Version 5.1.0 (updated March 2011). The Cochrane Collaboration, 2011. Available from www.cochranehandbook.org.

\section{Higgins 2011b}

Higgins JPT, Deeks JJ, Altman DG (editors). Chapter 16: Special topics in statistics. In: Higgins JPT, Green S editor(s). Cochrane Handbook for Systematic Reviewsof Interventions Version 5.1.0 (updated March 2011). The Cochrane Collaboration, 2011. Available from www.cochrane-handbook.org.

\section{Hill 2015}

Hill KP. Medical marijuana for treatment of chronic pain and other medical and psychiatric problems: A clinical review. JAMA 2015;313(24):2474-83.

\section{Irvine 1994}

Irvine EJ, Feagan B, Rochon J, Archambault A, Fedorak RN, Groll A, et al. Quality of life: a valid and reliable measure of therapeutic efficacy in the treatment of inflammatory bowel disease. Canadian Crohn's Relapse Prevention Trial Study Group. Gastroenterology 1994;106(2):287-96.

\section{Irvine 2008}

Irvine EJ. Quality of life of patients with ulcerative colitis: past, present, and future. Inflammatory Bowel Diseases 2008;14(4):554-65.

\section{Johnson 2005}

Johnson GJ, Cosnes J, Mansfield JC. Review article: smoking cessation as primary therapy to modify the course of Crohn's disease. Alimentary Pharmacology and Therapeutics 2005;21:921-31.

\section{Klein 2006}

Klein TW, Carbral GA. Cannabinoid-Induced immune suppression and modulation of antigen-presenting cells. Journal of Neuroimmune Pharmacology 2006;1:50-64.

\section{Lahat 2012}

Lahat A, Lang A, Ben-Horin S. Impact of cannabis treatment on the quality of life, weight and clinical disease activity in Inflammatory Bowel Disease patients: A pilot prospective study. Digestion 2012;85:1-8.

\section{Lal 2011}

Lal S, Prasad N, Ryan M, Tangri S, Silverberg MS, Gordon A, et al. Cannabis use amongst patients with inflammatory bowel disease. European Journal of Gastroenterology and Hepatology 2011;23(10):891-6.

\section{Langhorst 2015}

Langhorst J, Wulfert H, Lauche R, Klose P, Cramer H, Dobos GJ, et al. Systematic review of complementary and alternative medicine treatments in inflammatory bowel diseases. Journal of Crohn's and Colitis 2015;9(1):86-106.

\section{Marquez 2009}

Marquez L, Suarez J, Iglesias M, Bermudez-Silva FJ, Rodriguez deFonseca F, Andreu M. Ulcerative colitis induces changes on the expression of the endocannabinoid system in the human colonic tissue. PLoS ONE 2009;4(9):e6893.

\section{Massa 2004}

Massa F, Marsicano G, Hermann H, Cannich A, Monory K, Cravatt $B$, et al. The endogenous cannabinoid system protects against colonic inflammation. Journal of Clinical Investigation 2004;113(8):1202-9.

\section{Pinto 2002}

Pinto L, Izzo AA, Mascolo N, Capasso F, Cascio MG, Bisogno T, et al. Endocannabinoids as physiological regulators of colonic propulsion in mice. Gastroenterology 2002;123:227-34.

\section{Ramo 2012}

Ramo DE, Liu H, Prochaska JJ. Tobacco and marijuana use among adolescents and young adults: A systematic review of their co-use. Clinical Psychology Review 2012;32(2):105-21.

\section{Rubin 2004}

Rubin GP, Hungin AP, Chinn DJ, Dwarakanath D. Quality of life in patients with established inflammatory bowel disease: a UK general practice survey. Alimentary Pharmacology and Therapeutics 2004;19(5):529-35.

\section{Schauer 2016}

Schauer GL, Berg CJ, Kegler MC, Donovan DM, Windle M. Differences in tobacco product use among past month adult marijuana users and nonusers: Findings from the 2003-2012 national survey on drug use and health. Nicotine and Tobacco Research 2016;18(3):281-8.

\section{Schauer 2017}

Schauer GL, Rosenberry ZR, Peters EN. Marijuana and tobacco co-administration in blunts, spliffs, and mulled cigarettes: A systematic literature review. Addictive Behaviors 2017;64:200-11.

\section{Schünemann 2011}

Schünemann HJ, Oxman AD, Vist GE, Higgins JPT, Deeks JJ, Glasziou P, et al. Chapter 12: Interpreting results and drawing conclusions. In: Higgins JPT, Green S editor(s). Cochrane Handbook for Systematic Reviews of Interventions Version 5.1.0 (updated March 2011). The Cochrane Collaboration, 2011. Available from www.cochrane-handbook.org.

\section{Singh 2012}

Singh UP, Singh NP, Singh B, Price RL, Nagarkatti M, Nagarkatti PS. Cannabinoids Receptor-2 (CB2) agonist ameliorates colitis inIL-10-/- mice by attenuating the activation of T cells and promoting their apoptosis. Toxicology and Applied Pharmacology 2012;258(2):256-67.

\section{Storr 2014}

Storr M, Devlin S, Kaplan GG, Panaccione R, Andrews CN. Cannabis use provides symptom relief in patients with inflammatory bowel disease but is associated with worse 
disease prognosis in patients with Crohn's disease. Inflammatory Bowel Diseases 2014;20(3):472-80.

\section{Tibirica 2010}

Tibirica, E. The multiple functions of the endocannabinoid system: a focus on the regulation of food intake. Diabetology and Metabolic Syndrome 2010;2:5.

\section{Triantafillidis 2013}

Triantafillidis JK, Merikas Em Gikas A. Psychological factors and stress in inflammatory bowel disease. Expert Review of Gastroenterology and Hepatology 2013;7(3):225-38.

\section{Vianna 2012}

Vianna CR, Donato J, Rossi J, Scott M, Economides K, Gautron L, et al. Cannabinoid receptor 1 in the vagus nerve is dispensable for body weight homeostasis but required for normal gastrointestinal motility. Journal of Neuroscience 2012;32(30):10331-7.

\section{CHARACTERISTICS OF STUDIES}

Characteristics of included studies [ordered by study ID]

\section{Volz 2016}

Volz MS, Siegmund B, Hauser W. Efficacy, tolerability, and safety of cannabinoids in gastroenterology: A systematic review. Schmerz 2016;30(1):37-46.

\section{Weiss 2015}

Weiss A, Friedenberg F. Patterns of cannabis use in patients with Inflammatory Bowel Disease: A population based analysis. Drug and Alcohol Dependence 2015;156:84-9.

\section{Whiting 2015}

Whiting PF, Wolff RF, Deshpande S, Di Nisio M, Duffy S, Hernandez A, et al. Cannabinoids for medical use a systematic review and meta-analysis. JAMA 2015;313(24):2456-73.

\section{Wright 2005}

Wright K, Rooney N, Feeney M, Tate J, Robertson D, Welham M, et al. Differential expression of cannabinoid receptors in the human colon: Cannabinoids promote epithelial wound healing. Gastroenterology 2005;129(2):437-53.

* Indicates the major publication for the study

Naftali 2013a

Methods Randomized, single-centre, double-blind, placebo-controlled trial

Participants

Patients with an established diagnosis of Crohn's disease, at least 20 years of age, had active Crohn's disease (with a calculated CDAl score between 200 and 450 points), all patients had failed at least one form of medical treatment for the disease (including mesalamine, corticosteroids, thiopurines, methotrexate, or anti-TNF- $\alpha$. Anti-TNF- $\alpha$ failure was declared after at least 4 doses), patients receiving corticosteroids were on a stable dose for at least 1 month, and patients receiving thiopurines were on a stable dose for at least 3 months

22 patients were randomized, but 21 patients were studied

One patient declined participation after signing consent, but before receiving drug

Cannabis cigarettes containing $115 \mathrm{mg}$ of THC twice daily for 8 weeks $(n=11)$
Placebo with cannabis flowers from which the THC had been extracted for 8 weeks $(n=10)$
There was a 2 week follow-up visit after completion

Outcomes Primary outcome was induction of remission, defined as a CDAl score of 150 or less after 8 weeks of cannabis treatment

Secondary outcomes: response rate, determined 1) as a 100-point reduction in CDAI score from baseline, 2) a reduction of at least $0.5 \mathrm{mg}$ in CRP, or 3) improvement in quality of life of at least 50 points, as measured by the SF-36 health survey

\section{Risk of bias}


Naftali 2013a (Continued)

Random sequence genera- Low risk Block method in a 1:1 ratio was used for randomization tion (selection bias)

Allocation concealment Unclear risk
(selection bias)

Blinding of participants High risk

and personnel (perfor-

mance bias)

All outcomes

\author{
The participants were blinded in the study \\ The cigarettes in the treatment and placebo groups were identical in appear- \\ ance
}

The cigarettes containing active cannabis contained $23 \%$ THC and less than $0.5 \%$ cannabidiol The placebo was made of cannabis flowers from which the THC was extracted

Complete blinding of the participants was not easy to achieve due to the psychotropic effects of cannabis - most of the participants were able to correctly tell what group they belonged to

\begin{tabular}{|c|c|c|}
\hline $\begin{array}{l}\text { Blinding of outcome as- } \\
\text { sessment (detection bias) }\end{array}$ & Low risk & $\begin{array}{l}\text { Investigators were blinded throughout the study as per Dr. Naftali's email co } \\
\text { respondence }\end{array}$ \\
\hline Gutcomints & & $\begin{array}{l}\text { The code was opened only at the end of the study when all the patients fin- } \\
\text { ished their treatment }\end{array}$ \\
\hline
\end{tabular}

Incomplete outcome data Unclear risk
(attrition bias)

(attritio

Higher drop out rate in the placebo group $(n=3)$ compared to the cannabis group. $(n=1)$

All outcomes

The participant in the cannabis group did not wish to continue and there was no response from the drop outs in the placebo group

Selective reporting (re- Unclear risk
porting bias)

There is a difference in primary outcome in the final study report compared to their protocol on clinicaltrials.gov. For the final report the primary outcome was clinical remission $(\mathrm{CDAI} \leq 150)$, however the primary outcome in their protocol was clinical response (a 70-point reduction in CDAI). We note that the new primary outcome clinical remission is a more stringent outcome than clinical response

In addition, the protocol also included the secondary outcomes change in IL-10, IL-2, and TGF beta, which were not reported in the final study

\begin{tabular}{|c|c|c|}
\hline Other bias & High risk & $\begin{array}{l}\text { The cannabis group's patients were older than the placebo group by about } 10 \\
\text { years }(P=0.02)\end{array}$ \\
\hline
\end{tabular}

Naftali 2017a

Methods Randomized, single-centre, double-blind, placebo-controlled trial

Participants

\begin{abstract}
Participants were at least 20 years of age, had active Crohn's disease with a calculated CDAl score between 200 and 450 points, received at least one form of medical treatment for Crohn's disease with no effect (previous treatments included mesalamine, corticosteroids, thiopurines, methotrexate, or anti-TNF- $\alpha$ ), patients receiving corticosteroids were on a stable dose for at least 1 month, patients receiving thiopurines for at least 3 months, and patients receiving anti-TNF- $\alpha$ had received at least four infusions before failure was declared
\end{abstract}

19 patients completed the study 
Naftali 2017a (Continued)

21 patients were recruited, one withdrew consent before any consumption of the study drug and one was withdrawn due to colitis
$2 \mathrm{ml}$ twice daily of cannabis oil (cannabidiol $5 \%)$ for 8 weeks $(n=10)$

Placebo containing pure olive oil $2 \mathrm{ml}$ twice daily for 8 weeks $(n=9)$

Outcomes $\quad$ Primary outcome was reduction of 70 points in CDAI from week 0 to week 8

Secondary outcomes: Any adverse events within the time frame of 8 weeks; ability to stop steroids in patients who were treated with steroids at the beginning of the study; and reduction in at least $1 \mathrm{mg} / \mathrm{dl}$ in the CRP level

\section{Notes}

\section{Risk of bias}

\begin{tabular}{|c|c|c|}
\hline Bias & Authors' judgement & Support for judgement \\
\hline $\begin{array}{l}\text { Random sequence genera- } \\
\text { tion (selection bias) }\end{array}$ & Low risk & $\begin{array}{l}\text { Block method in 1:1 ratio. The patients were assigned to their treatment at the } \\
\text { order in which they entered the study }\end{array}$ \\
\hline $\begin{array}{l}\text { Allocation concealment } \\
\text { (selection bias) }\end{array}$ & Low risk & Numbered bottles and allocations were guarded in a closed, locked envelope \\
\hline $\begin{array}{l}\text { Blinding of participants } \\
\text { and personnel (perfor- } \\
\text { mance bias) } \\
\text { All outcomes }\end{array}$ & Low risk & $\begin{array}{l}\text { Participants were blinded to the treatment group assignment } \\
\text { Both the CBD oil and placebo oil were identical. "CBD was prepared by silica } \\
\text { gel column chromatography of a petroleum ether extract of Lebanese hashish, } \\
\text { which contains about } 5 \% \text { CBD, followed by crystallization with pentane to ob- } \\
\text { tain the material in } 99.5 \% \text { purity, which was then dissolved in olive oil. The } \\
\text { placebo was olive oil without any additions" }\end{array}$ \\
\hline
\end{tabular}

Blinding of outcome as- Low risk sessment (detection bias) All outcomes
Investigators were blinded, the bottles were numbered and none of the clinical investigators had the code

\begin{tabular}{|c|c|c|}
\hline $\begin{array}{l}\text { Incomplete outcome data } \\
\text { (attrition bias) } \\
\text { All outcomes }\end{array}$ & Low risk & No dropouts between the treatment and placebo groups \\
\hline $\begin{array}{l}\text { Selective reporting (re- } \\
\text { porting bias) }\end{array}$ & Unclear risk & $\begin{array}{l}\text { The authors did not report on their pre-specified primary outcome clinical re- } \\
\text { sponse (reduction of } 70 \text { points in CDAI from week } 0 \text { to week } 8 \text { ) - however the } \\
\text { authors do report on clinical remission which is a more stringent outcome } \\
\text { than clinical response }\end{array}$ \\
\hline & & $\begin{array}{l}\text { The final study report also did not report on some of their pre-specified sec- } \\
\text { ondary outcomes (reduction in at least } 1 \mathrm{mg} / \mathrm{dl} \text { in the CRP level) }\end{array}$ \\
\hline
\end{tabular}

\begin{tabular}{ll}
\hline Other bias $\quad$ High risk & There were more smokers in the cannabinoid group than the placebo group $(6$ \\
vs. $0, P<0.05)$
\end{tabular}

\section{Naftali 2017b}

\begin{tabular}{ll}
\hline Methods & Randomized, double-blind, placebo-controlled trial \\
\hline Participants & Patients with active Crohn's disease $(\mathrm{N}=50)$ \\
\hline \hline
\end{tabular}


Naftali 2017b (Continued)

Interventions Cannabis oil ( $15 \%$ cannabidiol and $4 \%$ THC) for 8 weeks $(n=24)$

Placebo oil for eight weeks $(n=26)$

Abstract did not specify primary outcome
Outcomes included: CDAl, inflammatory markers and quality of life (SF-36)
These outcomes were assessed before, during and after treatment

Notes Additional information was supplied by the principal investigator Tima Naftali which informed our risk of bias assessment

NCT01826188

\section{Risk of bias}

\begin{tabular}{lll}
\hline Bias & Authors' judgement & Support for judgement \\
\hline $\begin{array}{l}\text { Random sequence genera- } \\
\text { tion (selection bias) }\end{array}$ & Low risk & $\begin{array}{l}\text { Participants were randomly assigned using block method in a 1:1 ratio to re- } \\
\text { ceive either cannabis oil or placebo oil }\end{array}$ \\
\hline $\begin{array}{l}\text { Allocation concealment } \\
\text { (selection bias) }\end{array}$ & Low risk & $\begin{array}{l}\text { The investigators used sequentially numbered drug containers of identical ap- } \\
\text { pearance, which were given to the patients outside of the hospital by the phar- } \\
\text { macy staff so the medical team did not see them }\end{array}$ \\
\hline
\end{tabular}

$\begin{array}{ll}\begin{array}{l}\text { Blinding of participants } \\ \text { and personnel (perfor- }\end{array} & \text { Low risk }\end{array}$
mance bias)

All outcomes

\begin{tabular}{|c|c|c|}
\hline $\begin{array}{l}\text { Blinding of outcome as- } \\
\text { sessment (detection bias) }\end{array}$ & Low risk & Outcome assessors were blinded \\
\hline All outcomes & & Blinding was open only at the end of the study \\
\hline
\end{tabular}

Incomplete outcome data Low risk There were no drop-outs
(attrition bias)
All outcomes

\begin{tabular}{|c|c|c|}
\hline $\begin{array}{l}\text { Selective reporting (re- } \\
\text { porting bias) }\end{array}$ & Unclear risk & $\begin{array}{l}\text { The primary outcome reported in the study protocol was a reduction in CDAI } \\
\text { of } 100 \text { points }\end{array}$ \\
\hline
\end{tabular}

The secondary outcomes reported in the study protocol included clinical remission (CDAl $\leq 150)$, improvement in at least one point in endoscopic disease activity index, improvement in C-reactive protein and fecal calprotectin, improvement in blood cytokine levels, quality of life (SF-36) and adverse events

Quality of life was reported in the abstract publication - the other outcomes could potentially be reported in a full manuscript

Other bias Low risk This study appears to be free of other sources of bias

CDAl: Crohn's disease activity index

TNF-a: Tumor-necrosis factor-alpha

THC: D9-tetrahydrocannabinol

CRP: C-reactive protein

SF-36: Short-Form 36 health survey 
Characteristics of excluded studies [ordered by study ID]

\begin{tabular}{ll}
\hline Study & Reason for exclusion \\
\hline Naftali 2013b & We were not able to acquire separate data for participants with Crohn's disease \\
& The study included 10 participants with ulcerative colitis and 22 participants with Crohn's disease \\
& Results were reported for both groups combined \\
\hline
\end{tabular}

Characteristics of ongoing studies [ordered by study ID]

NCT03467620

\begin{tabular}{ll}
\hline Trial name or title & Cannabidiol Usage as an Adjunct Therapy for Crohn's Disease \\
\hline Methods & $\begin{array}{l}\text { A pilot randomized, placebo-controlled trial assessing the efficacy and safety of oral cannabinoids } \\
\text { as an adjunct therapy in patients with Crohn's disease }\end{array}$ \\
\hline Inclusion Criteria: & Age 18 or older \\
& English-speaking \\
& Ileal and/or ileocolonic involvement as demonstrated by most recent endoscopy \\
& Short CDAl score > 150 \\
& Have not received oral or intravenous steroids for $>1$ month, or with stable dose for $>1$ month if cur- \\
rently taking & Stable dose of AZA for $>1$ month, if currently taking \\
& Stable dose of anti-TNF inhibitor for $>1$ month, if currently taking \\
& Exclusion Criteria: \\
Pregnant or intend to become pregnant in the next 6 months & Major abdominal surgery within the past 3 months
\end{tabular}

Interventions Cannabidiol oral capsule: $25 \mathrm{mg}$ capsule of Cannabidiol (CBD) per day taken daily for a duration of 12 weeks

Placebo: Placebo oral, one per day for a duration of 12 weeks

\begin{tabular}{ll}
\hline Outcomes & Primary: A decrease in CDAl score (Clinical Disease Activity Index) score [12 weeks ] \\
A decrease in fecal calprotectin [12 weeks ] & Secondary: Rates of hospitalizations and adverse events [12 weeks] \\
\hline Starting date & July 2018 \\
\hline Contact information & Contact: Kyle M Geary, MD \\
Phone:312-355-1700 \\
Email: kgeary3@uic.edu
\end{tabular}


NCT03467620 (Continued)

DATA AND ANALYSES

Comparison 1. Cannabis cigarettes (115 mg THC) versus placebo cigarettes

\begin{tabular}{|c|c|c|c|c|}
\hline Outcome or subgroup title & No. of studies & $\begin{array}{l}\text { No. of partici- } \\
\text { pants }\end{array}$ & Statistical method & Effect size \\
\hline 1 Clinical remission at 8 weeks & 1 & & $\begin{array}{l}\text { Risk Ratio (M-H, Fixed, 95\% } \\
\mathrm{Cl} \text { ) }\end{array}$ & Totals not selected \\
\hline 2 Clinical response at 8 weeks & 1 & & $\begin{array}{l}\text { Risk Ratio (M-H, Fixed, 95\% } \\
\mathrm{Cl})\end{array}$ & Totals not selected \\
\hline 3 Adverse events & 1 & & $\begin{array}{l}\text { Risk Ratio (M-H, Fixed, 95\% } \\
\mathrm{Cl} \text { ) }\end{array}$ & Totals not selected \\
\hline $\begin{array}{l}4 \text { Decrease in CRP of more than } 0.5 \\
\mathrm{mg} / \mathrm{dL} \text { from week } 0 \text { to week } 8\end{array}$ & 1 & & $\begin{array}{l}\text { Risk Ratio (M-H, Fixed, 95\% } \\
\mathrm{Cl} \text { ) }\end{array}$ & Totals not selected \\
\hline
\end{tabular}

Analysis 1.1. Comparison 1 Cannabis cigarettes (115 mg THC) versus placebo cigarettes, Outcome 1 Clinical remission at 8 weeks.

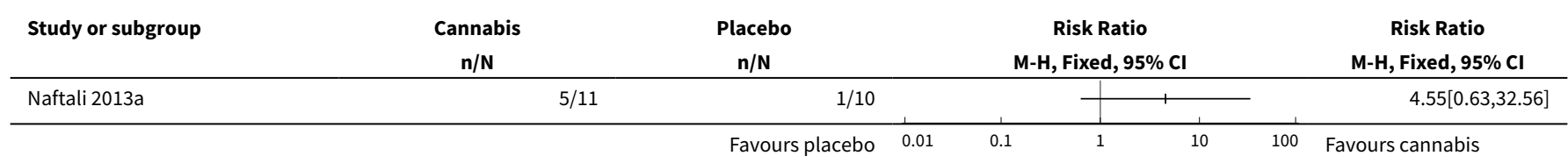

Analysis 1.2. Comparison 1 Cannabis cigarettes (115 mg THC) versus placebo cigarettes, Outcome 2 Clinical response at 8 weeks.

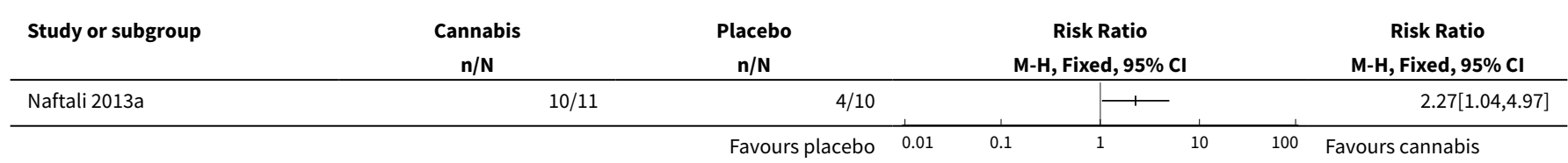

Analysis 1.3. Comparison 1 Cannabis cigarettes (115 mg THC) versus placebo cigarettes, Outcome 3 Adverse events.

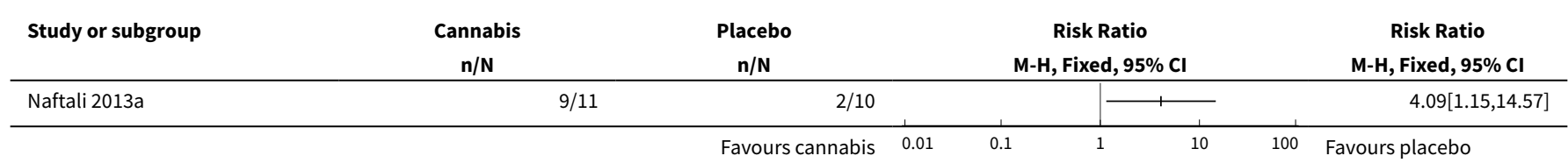


Analysis 1.4. Comparison 1 Cannabis cigarettes (115 mg THC) versus placebo cigarettes, Outcome 4 Decrease in CRP of more than $0.5 \mathrm{mg} / \mathrm{dL}$ from week 0 to week 8 .

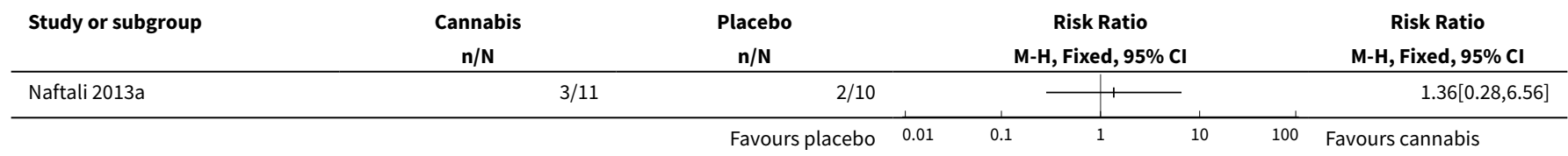

Comparison 2. Cannabis oil ( $5 \%$ cannabidiol sublingual oil) versus placebo oil

\begin{tabular}{lllll}
\hline Outcome or subgroup title & No. of studies & $\begin{array}{l}\text { No. of partici- } \\
\text { pants }\end{array}$ & Statistical method & Effect size \\
\hline 1 Clinical remission at 8 weeks & 1 & Risk Ratio (M-H, Fixed, 95\% Cl) & Totals not selected \\
\hline 2 Serious adverse events & 1 & Risk Ratio (M-H, Fixed, 95\% Cl) & Totals not selected \\
\hline
\end{tabular}

Analysis 2.1. Comparison 2 Cannabis oil ( $5 \%$ cannabidiol sublingual oil) versus placebo oil, Outcome 1 Clinical remission at 8 weeks.

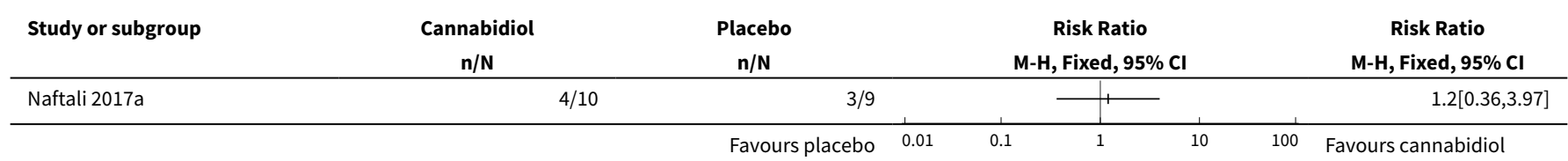

Analysis 2.2. Comparison 2 Cannabis oil (5\% cannabidiol sublingual oil) versus placebo oil, Outcome 2 Serious adverse events.

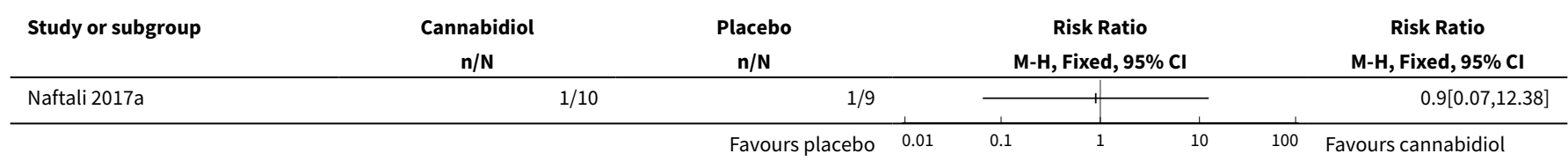

Comparison 3. Cannabis oil (15\% cannabidiol and $4 \%$ THC) versus placebo oil

\begin{tabular}{lllll}
\hline Outcome or subgroup title & No. of studies & $\begin{array}{l}\text { No. of partici- } \\
\text { pants }\end{array}$ & Statistical method & Effect size \\
\hline 1 Quality of life at 8 weeks & 1 & Mean Difference (IV, Fixed, 95\% CI) & Totals not selected \\
\hline 2 CDAl at 8 weeks & 1 & Mean Difference (IV, Fixed, 95\% CI) & Totals not selected \\
\hline
\end{tabular}


Analysis 3.1. Comparison 3 Cannabis oil ( $15 \%$ cannabidiol and $4 \%$ THC) versus placebo oil, Outcome 1 Quality of life at 8 weeks.

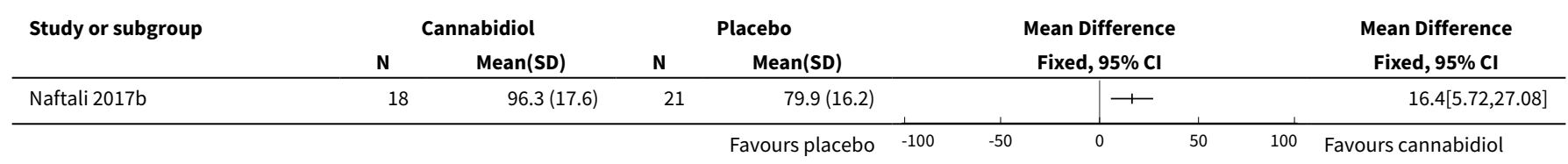

Analysis 3.2. Comparison 3 Cannabis oil (15\% cannabidiol and $4 \%$ THC) versus placebo oil, Outcome 2 CDAl at 8 weeks.

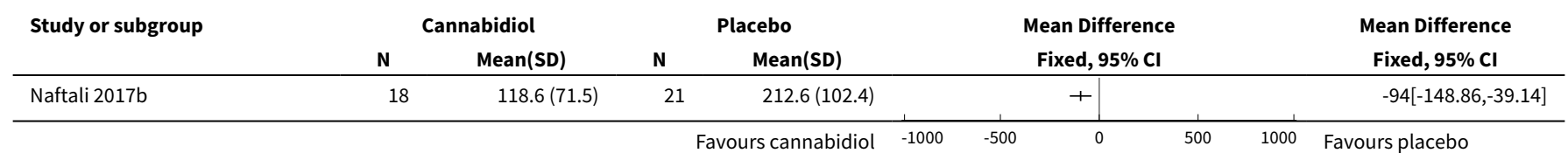

\section{APPEN DICES}

\section{Appendix 1. Appendix 1 - Search Strategy}

\section{MEDLINE}

1. random\$.tw.

2. factorial\$.tw.

3. (crossover\$ or cross over\$ or cross-over\$).tw.

4. placebo\$.tw.

5. single blind.mp.

6. double blind.mp.

7. triple blind.mp.

8. (singl\$ adj blind\$).tw.

9. (double\$ adj blind\$).tw.

10. (tripl\$ adj blind\$).tw.

11. assign\$.tw.

12. allocat\$.tw.

13. crossover procedure/

14. double blind procedure/

15. single blind procedure/

16. triple blind procedure/

17. randomized controlled trial/

18. or/1-17 


\section{Exp Crohn disease/}

20. Crohn ${ }^{\star} \cdot \mathrm{mp}$.

21. IBD.mp.

22. Inflammatory bowel disease ${ }^{\star} . \mathrm{mp}$.

23. $\mathrm{Or} / 19-22$

24. Exp Marijuana/

25. Cannabis*.mp.

26. Weed ${ }^{*}$.mp.

27. Marijuana*.mp.

28. Cannabi*.mp.

29. Dronabinol.mp.

30. Cannabichromene.mp.

31. 8-THC.mp.

32. Nabilone.mp.

33. Tetrahydrocannabivarin.mp.

34. $\mathrm{Or} / 24-33$

35. 18 and 23 and 34

\section{EMBASE}

1. random\$.tw.

2. factorials.tw.

3. (crossover\$ or cross over\$ or cross-over\$).tw.

4. placebo\$.tw.

5. single blind.mp.

6. double blind.mp.

7. triple blind.mp.

8. (singl\$ adj blind\$).tw.

9. (double\$ adj blind\$).tw.

10. (tripl\$ adj blind\$).tw.

11. assign\$.tw.

12. allocat\$.tw.

13. crossover procedure/

14. double blind procedure/

15. single blind procedure/

16. triple blind procedure/

17. randomized controlled trial/

Cannabis for the treatment of Crohn's disease (Review) 
18. or/1-17

19. Exp Crohn disease/

20. Crohn*.mp.

21. IBD.mp.

22. Inflammatory bowel disease ${ }^{\star} . \mathrm{mp}$.

23. $\mathrm{Or} / 19-22$

24. Exp Marijuana/

25. Cannabis*.mp.

26. Weed ${ }^{\star} . \mathrm{mp}$.

27. Marijuana*.mp.

28. Cannabi*.mp.

29. Dronabinol.mp.

30. Cannabichromene.mp.

31. 8-THC.mp.

32. Nabilone.mp.

33. Tetrahydrocannabivarin.mp.

34. Or/24-33

35. 18 and 23 and 34

\section{AMED (Allied \& Alternative Medicine)}

1. Exp Crohn disease/

2. Crohn*.mp.

3. IBD.mp.

4. Inflammatory bowel disease*.mp.

5. $\mathrm{Or} / 1-4$

6. Marijuana.mp.

7. Cannabis*.mp.

8. Weed*.mp.

9. Marijuana*.mp.

10. Cannabi*.mp.

11. Dronabinol.mp.

12. Cannabichromene.mp.

13. 8 THC.mp.

14. Nabilone.mp.

15. Tetrahydrocannabivarin.mp.

16. $\mathrm{Or} / 6-15$

Cannabis for the treatment of Crohn's disease (Review) 
17.5 and 16

\section{Psych INFO}

ti((Cannabi* OR marijuana OR weed* OR droning OR Cannabichromene OR 8-tic OR Nabilone OR Tetrahydrocannabivarin)) AND ti((croon Disease OR Inflammatory Bowel Disease OR cud))

\section{CENTRAL}

\#1 MeSH: [Inflammatory bowel disease] explode all trees

\#2 Crohn Disease

\#3 Crohn

\#4 IBD

\#5 \#1 or \#2 or \#3 or \#4

\#6 MeSH: [Cannabis] explode all trees

\#7 Cannabis

\#8 Marijuana

\#9 Weed

\#10 cannabinoid

\#11 cannabidiol

\#12 cannabigerol

\#13 dronabinol

\#14 cannabichromene

\#15 8 THC

\#16 Nabilone

\#17 Tetrahydrocannabivarin

$\# 18 \# 7$ or \#8 or \#9 or \#10 or \#11 or \#12 or \#13 or \#14 or \#15 or \#16 or \#17

$\# 19 \# 5$ and \#18

\section{Clinical Trials. Gov}

1. Cannabis and Crohn's Disease

2. Marijuana and Crohn's Disease

\section{https://www.clinicaltrialsregister.eu/ (European clinical trials register)}

1. Cannabis and Crohn's Disease

2. Marijuana and Crohn's Disease

3. Cannabis and inflammatory bowel disease

\section{WHAT'S NEW}

\begin{tabular}{lll}
\hline Date & Event & Description \\
\hline 4 June 2019 & Amended & Correction to article metadata; no impact on article content \\
\hline \hline
\end{tabular}

Cannabis for the treatment of Crohn's disease (Review)

Copyright $\odot 2019$ The Cochrane Collaboration. Published by John Wiley \& Sons, Ltd. 


\section{HISTORY}

Protocol first published: Issue 11, 2017

Review first published: Issue 11, 2018

\begin{tabular}{lll}
\hline Date & Event & Description \\
\hline 24 May 2019 & Amended & Correction of minor error in reporting of adverse event results \\
\hline
\end{tabular}

\section{CONTRIBUTIONS OF AUTHORS}

All authors contributed to the development and writing of the protocol. All authors contributed to writing the final manuscript.

\section{DECLARATIONS OF INTEREST}

Tahir S Kafil: None known

Tran M Nguyen: None known

John K MacDonald: None known

Nilesh Chande has received funds from AbbVie, Ferring, and Takdeda for consulting; and payment for lectures from Abbvie and Actavis. All of these financial activities are outside the submitted work.

\section{DIFFERENCES BETWEEN PROTOCOL AND REVIEW}

We added clinical response as a secondary outcome measure as we forgot to include this outcome in the protocol.

\section{INDEX TERMS}

\section{Medical Subject Headings (MeSH)}

*Phytotherapy [adverse effects]; Cannabidiol [adverse effects] [ ${ }^{*}$ therapeutic use]; Crohn Disease [ ${ }^{*}$ drug therapy]; Disease Progression; Dronabinol [adverse effects] [ ${ }^{\star}$ therapeutic use]; Marijuana Smoking; Medical Marijuana [adverse effects] [ ${ }^{\star}$ therapeutic use]; Quality of Life; Randomized Controlled Trials as Topic; Remission Induction

\section{MeSH check words}

Adult; Humans 